\title{
The Contribution of Wind-Generated Waves to Coastal Sea-Level Changes
}

\author{
Dodet Guillaume ${ }^{1,}{ }^{*}$, Melet Angélique ${ }^{2}$, Ardhuin Fabrice ${ }^{6}$, Bertin Xavier ${ }^{3}$, Idier Déborah ${ }^{4}$, \\ Almar Rafael ${ }^{5}$
}

1 UMR 6253 LOPSCNRS-Ifremer-IRD-Univiversity of Brest BrestPlouzané, France

2 Mercator OceanRamonville Saint Agne, France

3 UMR 7266 LIENSs, CNRS - La Rochelle UniversityLa Rochelle, France

4 BRGMOrléans Cédex, France

${ }^{5}$ UMR 5566 LEGOSToulouse Cédex 9, France

*Corresponding author : Guillaume Dodet, email address : guillaume.dodet@univ-brest.fr

\begin{abstract}
:
Surface gravity waves generated by winds are ubiquitous on our oceans and play a primordial role in the dynamics of the ocean-land-atmosphere interfaces. In particular, wind-generated waves cause fluctuations of the sea level at the coast over timescales from a few seconds (individual wave runup) to a few hours (wave-induced setup). These wave-induced processes are of major importance for coastal management as they add up to tides and atmospheric surges during storm events and enhance coastal flooding and erosion. Changes in the atmospheric circulation associated with natural climate cycles or caused by increasing greenhouse gas emissions affect the wave conditions worldwide, which may drive significant changes in the wave-induced coastal hydrodynamics. Since sea-level rise represents a major challenge for sustainable coastal management, particularly in low-lying coastal areas and/or along densely urbanized coastlines, understanding the contribution of wind-generated waves to the long-term budget of coastal sea-level changes is therefore of major importance. In this review, we describe the physical processes by which sea states may affect coastal sea level at several timescales, we present the methods currently used to estimate the wave contribution to coastal sea-level changes, we describe past and future wave climate variability, we discuss the contribution of wave to coastal sea-level changes, and we discuss the limitations and perspectives of this research field.
\end{abstract}

Keywords : Wind waves, Sea level, Coastal zone, Climate change 


\section{1. Introduction}

Waves often play a significant role in high sea levels and inundations at the coast, whether associated to a local wind storm or to swells from a remote storm (Hoeke et al. 2013, Ford et al. 2018). This wave activity has a strong regional and interannual variability (Bromirski et al. 2005) and long-term trends in offshore significant wave height (Hs) exhibit strong regional variations, with possible trends of a few centimeters per year for the

35 90th percentile of offshore Hs (Wang and Swail, 2002). The wave-driven contribution to the total water level generally varies with shoreline morphology and sea state properties and can be a fraction of the offshore $H s$ that ranges from 10 to 200\% (e.g. Stockdon et al. 2006, Poate et al. 2016). As a result, wave-driven contributions to the water level can contribute substantially to trends in coastal sea level (Melet et al. 2018).

40 The contribution of wave to coastal sea level adds to ocean dynamic sea level rise (Gregory et al. 2019) and, 
where wave height or wave periods increase, enhances the threat to coastal zones (Cazenave and Le Cozannet, 2014), or mitigates the threat where heights or periods decrease. First, because a higher sea level increases the frequency and amplitude of coastal hazards, such as flooding and erosion, but also because the social and economic stakes of the coasts have never been so valuable and fragile at the same time. Indeed, the increase in population density in coastal regions during the industrial period has fostered the urbanization of many coastlines of the world, enhancing their socio-economic importance but also weakening their resilient capacity (Neumann et al. 2015). Therefore, densely populated and/or highly urbanized coastlines now require a detailed understanding of coastal sea level changes, with possible costly adaptation strategy and accurate early warning systems in order to maintain economic activities and population safety.

50

Since the early 1990's, satellite altimetry has provided a comprehensive view of the global distribution of sea level changes (Cazenave et al. 2018). However, these results concern the open ocean and, presently, cannot be easily extrapolated to the coastal regions. Indeed, coasts represent an important source of noise in radar altimetry, which prevents an accurate estimation of sea level closer than about $20 \mathrm{~km}$ from the coast (Cipollini et

55 al. 2017). In addition, the coastal shelf and more particularly the narrow wave breaking zone (with width of the order $10^{1}-10^{4} \mathrm{~m}$, Wright and Short, 1984) is a very dynamic region that exhibits rapid changes in sea level and currents, as a result of the complex interactions between the waves and the sea floor (Munk and Traylor 1947). Indeed, wind generated waves accumulate and transport momentum across ocean basins and release it to the water column when they break in the shallow surf zone. The rapid decrease in momentum flux is compensated

60 by a tilting of the water surface between the breakpoint and the waterline (Longuet-Higgins and Stewart, 1964), which can rise the time-averaged sea level at the waterline by up to $1 \mathrm{~m}$ (Pedreros et al. 2018; Guérin et al. 2018; Dodet et al. 2018). This effect, called the wave setup, is modulated by long waves with periods of the order of one minute that travel at the speed of the wave groups and rapidly grow (from centimeters to decimeters) in the surf zone. These waves are called infragravity waves. Finally, the wave runup, which is the highest waterline elevation reached by individual waves, integrates both the setup and infragravity waves plus a short-wave component, and represents an important contributor of the total water level. Since the wave runup is directly responsible for wave overtopping, it is crucial to take it into account for the design of coastal defences. The wave setup, wave runup and infragravity waves are all directly controlled by incident wave conditions and nearshore bathymetry.

70

Similarly to the atmospheric circulation, the average wave fields present coherent patterns at the basin scale that can be described with statistical parameters. The wave climate integrates the effect of both distant and local wind conditions, which makes the interpretation of observed variabilities particularly challenging. Thanks to long-term wave buoy records, spectral wave models and satellite-based wave observations, the different modes

75 of variability of the wave climate have been well investigated. The strong interannual variability of $H s$ at high latitudes and its link with climate modes such the North Atlantic Oscillation (NAO), the Pacific Decadal Oscillation (PDO) or the Southern Annular Mode (SAM) has been evidenced in several studies (e.g. Dodet et al. 2010; Hemer et al. 2012; Bromirski et al. 2013). Similar findings were obtained for extreme wave heights based on wave buoy and satellite observations (Menéndez et al. 2008; Izaguirre et al. 2011). Analysis of satellite-based wave observations over the period 1985-2008 highlighted the existence of significant trends in $\mathrm{Hs}$ in several 
regions of the world, more pronounced for the 90th and 99th percentiles of Hs (Young et al. 2011). However, given the relatively short time coverage of this data set, it is likely that the observed trend values are mostly influenced by decadal climate oscillations. Bertin et al. (2013) analysed the outputs of a 109-year numerical wave hindcasts for the North Atlantic and found significant trends in Hs in the North-East Atlantic, in the absence of any trends in NAO over the same period. While these long-term trends could be the result of external climate variability, the time-consistency of the wind field reanalysis that feed wave hindcasts remains a major issue to be solved for gaining confidence in such results (e.g. Stopa et al. 2019). Nevertheless, given the significant contribution of wave-induced processes to coastal sea level, changes in the wave conditions over decadal or longer time scales will likely contribute to coastal sea level changes and need to be further investigated.

The objective of this review paper is to discuss the current state of knowledge on wind generated wave contributions to coastal sea level changes, how these contributions are observed and modelled, and to identify future research needs in that regard. In the following section (Section 2), we describe the main physical processes through which wind generated waves can affect coastal sea level. In Section 3, we introduce the methods used to characterize offshore significant wave conditions and we present our current understanding on past and future wave conditions. coastal sea level and wave conditions. In Section 4, we present the method used to estimate nearshore parameters required to investigate coastal sea level and we discuss the impact of waves on coastal sea level. Finally, in Section 5, we present the current limitations of our understanding of the wave impact on coastal sea level and we mention several perspectives that could improve our understanding in the near future

\section{Physical processes}

Wave-induced processes control the nearshore hydrodynamics of exposed coastline and cause fluctuations of the coastal sea level over a wide range of timescales. Three main processes are identified and correspond to distinct, yet overlapping, spatial and temporal scales. These processes and their associated scales are depicted in Figure 1. First, infragravity waves (Fig.1 A and D), which travel in opposite phase with the wave groups they are bounded to, have typical periods of $\sim 1$ minute and wavelength of $\sim 10 \mathrm{~km}$. Second, the wave setup (Fig.1 B and E), which develops in the surf zone, may extend from a dozen of meters in steep environments to several kilometers in low-sloping environments during stormy conditions. Since the magnitude of the wave setup is mostly controlled by the offshore significant wave height, period and spectrum shape (Guza and Feddersen 2012), its magnitude varies with local wind sea and swell conditions, from a few hours to several days. Third, the wave runup (Fig.1 C and F), which corresponds to the fluctuations of the highest instantaneous water level across the swash zone, extends from a few meters in reflective environments to a hundred meters in dissipative environments. Its timescale is controlled by the relative contribution of incident (periods of $\sim 10$ s ) and infragragravity (periods of $\sim 1 \mathrm{~min}$ ) wave energy that reach the shoreline after the incident waves have broken. These three processes all contribute to the total coastal sea level, which is here defined as the sum of the mean sea level (e.g. averaged over one year), the astronomical tide, the atmospheric surge (inverse barometer effect and wind-induced surge) and the wave runup. The wave runup is composed of a steady component, the wave 
and a low frequency (infragravity waves) component. The following paragraphs present these processes in more details.

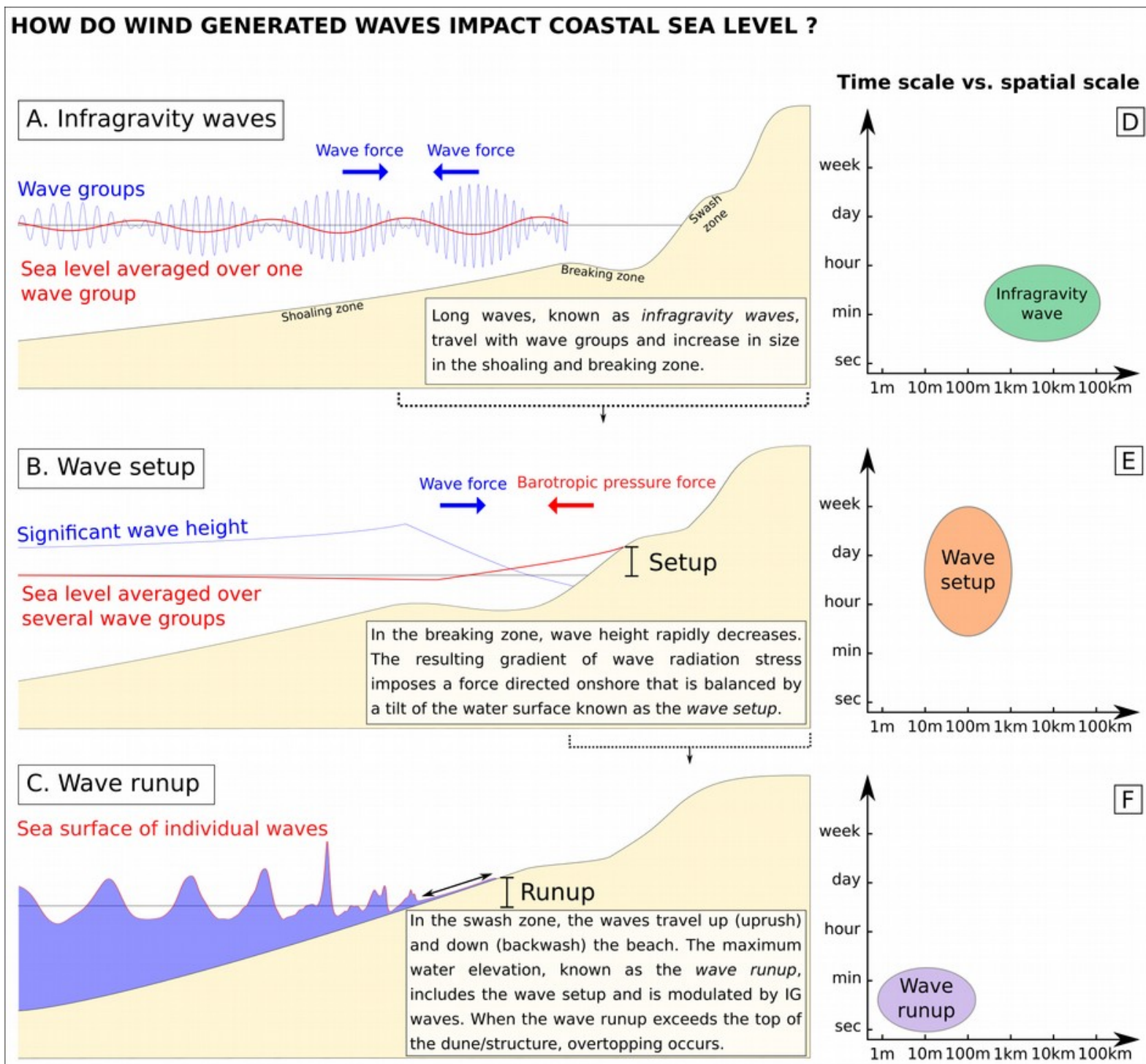

Fig.1 Schematic description of wave-induced processes impacting coastal sea level and their associated temporal and spatial scales for (a-d) infragravity waves; (b-e) wave setup; and (c-f) wave runup. The horizontal dotted black line represents the still water level, which includes the mean sea level, the astronomical tide and the atmospheric surge components.

\subsection{Wave setup}

Wave setup corresponds to the increase in mean water level along the shoreline associated with the dissipation of wind generated waves in the nearshore and was first reported by Saville (1961). It is usually measured relative to the still water level, defined here as the mean sea level outside the surf zone, including the astronomical tide and the atmospheric surge. Wave setup was investigated based on field observations for

135 several decades (e.g. Guza and Thornton, 1981; Holman and Sallenger, 1985; Raubenheimer et al. 2001; Apotsos et al. 2007, Nicolae-Lerma et al. 2017; Guérin et al. 2018). Wave setup can exceed 1 m under storm waves (Pedreros et al. 2018; Guérin et al. 2018; Dodet et al. 2018) and can therefore have a relevant 
contribution in storm surges. As a rough guideline, wave setup along the shoreline of sandy beaches represent about 10 to $20 \%$ of the significant wave height at the breaking point. Along the coasts bordered by narrow continental shelves or at volcanic islands, wave setup can even represent the largest contribution of storms surges (e.g. Kennedy et al. 2012; Bertin et al. 2017; Pedreros et al. 2018). Several studies also showed that the setup driven by wave breaking over the ebb deltas of shallow inlets (Malhadas et al. 2009; Dodet et al. 2013) and large estuaries (Bertin et al. 2015; Fortunato et al. 2017; Bertin et al. 2017) could propagate outside surfzones and raise the water level at the scale of the whole lagoon/estuary. The tilting of the free surface elevation resulting from wave setup induces a barotropic pressure gradient, which partly drives a bed return flow or undertow (Garcez-Faria et al. 2000), which is one of the main processes responsible for coastal erosion.

The first theoretical explanation for the development of wave setup is due to Longuet-Higgins and Stewart (1964), who introduced the concept of radiation stresses, which correspond to the wind generated wave momentum flux. In the nearshore, the depth-limited dissipation of short waves causes a strong gradient of radiation stress, which acts as a horizontal pressure force towards the shore and tilts the water level until a balance is reached with the subsequent barotropic pressure gradient. As a result, the mean water level near the breaking point lowers (set-down) and the mean water level at the shoreline rises (set-up). This wave-induced deformation of the water level was successfully reproduced in a wave channel by Bowen et al. (1968), as shown in Figure 2.

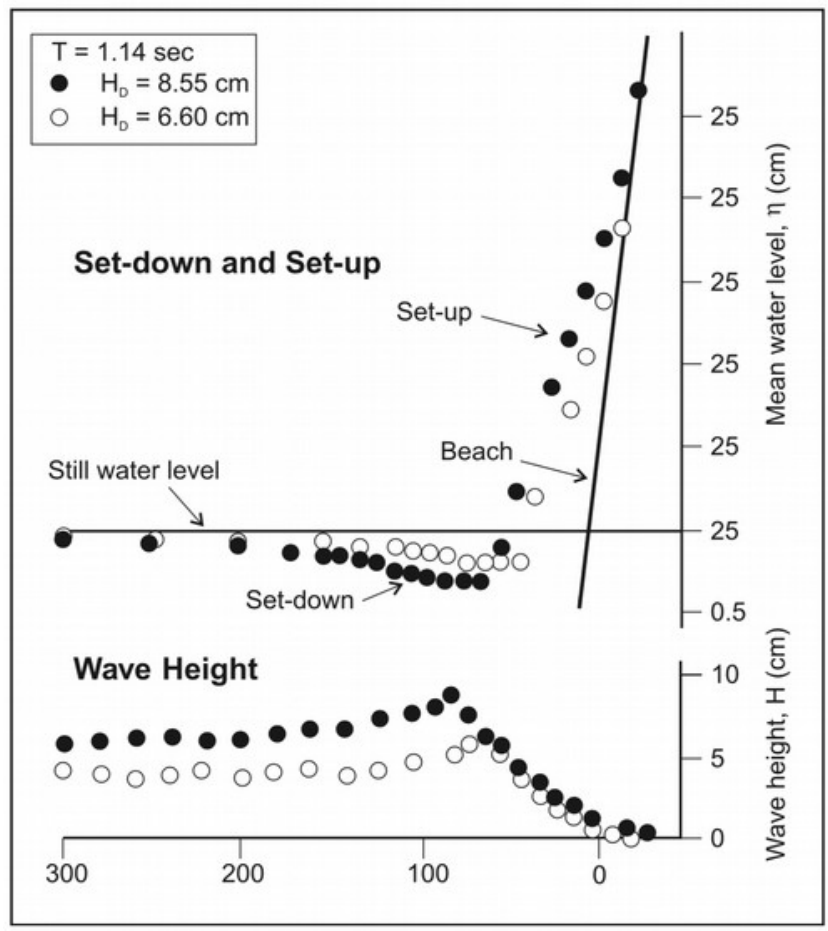

Fig.2 Profile of the mean water level and the envelope of the wave height for two experiments of Bowen et al. (1968) with wave period $=1.14 \mathrm{sec}, \mathrm{Hs}=6.60 \mathrm{~cm}$ and $\mathrm{Hs}=8.55 \mathrm{~cm}$. Reproduced from Bowen et al. 1969

Infragravity (hereafter IG) waves are surface gravity waves with frequencies typically ranging from 0.004 to $0.04 \mathrm{~Hz}$ and related to the presence of groups in incident short waves (see Bertin et al. 2018 for a recent review). 
While IG waves are only a few millimeters to a few centimeters high in the deep ocean (e.g. Rawat et al. 2014; Crawford et al. 2015; Smit et al. 2018), they grow in the nearshore and their height can exceed $1 \mathrm{~m}$ at the 165 shoreline (see Ruessink, 2010; Sheremet et al. 2014; Fiedler et al. 2015; Inch et al. 2017). As a consequence, IG waves have a relevant contribution to the nearshore hydrodynamics, particularly under storm waves (e.g. Guza and Thornton, 1982; Elgar et al. 1992; Ruessink et al. 1998).

Two main mechanisms typically explain the development of IG waves in the nearshore. First, the divergence of 170 the momentum flux associated with the short waves at the scale of wave groups drives the development of a long bound wave, out of phase with the energy envelope of the short waves (Biésel 1952; Longuet Higgins and Steward 1962). Hasselmann (1962) proposed an analytical solution to compute the bound wave for 2D random waves, which implies that the bound wave increases with the energy of the short wave, particularly when this energy is distributed over narrow-banded spectra. Second, due to the presence of wave groups, the cross-shore position of the breaking point varies in time and the equilibrium in the surfzone between the gradient of wave radiation stress and the subsequent barotropic pressure gradient becomes dynamic (see previous section and Figure 1b). This process generates IG waves radiating from the breaking point seaward and shoreward (Symonds et al. 1982). Battjes et al. (2004) showed that the former mechanism is dominant at gently sloping beaches while the latter is dominant in steep surfzones, such as in coral reefs (e.g. Pomeroy et al. 2012).

180 However, a recent study of Moura and Baldock (2007) questioned these well-admitted findings and suggests that the breakpoint mechanism could also be dominant for wide surfzones under spilling breakers. Cheriton et al. (2016) and Gawehn et al. (2016) further showed that IG waves can trigger resonant processes in coral reefs, which result in the development of very low frequency motions.

185 In the surf zone, the dissipation of short waves through depth-limited breaking reduces their groupiness, so that IG waves are no longer bound and can propagate as free waves (Battjes et al. 2004). In the inner surfzone, IG waves transfer energy to higher frequencies, which results in their steepening and can lead to their dissipation by breaking, particularly at gently sloping beaches (Battjes et al. 2004; De Bakker et al. 2014). As beaches usually display a steeper profile in their upper part - called the berm -, IG wave dissipation at high tide is reduced and

190 IG waves can dominate the runup (Ruggiero et al. 2004; Fiedler et al. 2015). The IG wave energy that is not dissipated can be reflected offshore, where it can be trapped by refraction and promote the development of edge waves (Bowen and Guza, 1978) or be leaked and propagate through the ocean with little dissipation (Rawat et al. 2014).

\subsection{Wave runup}

When wind generated waves reach the shores, they travel up (uprush) and down (backwash) the beach before being reflected seawards. This water displacement is called the swash, and the beach extent over which it occurs is the swash zone. The maximum vertical excursion of the waterline - called the wave runup - is usually measured with respect to the still water level, as for the wave setup. Therefore, the wave runup includes the contribution of both the swash and the wave setup. The swash energy is usually decomposed into a high frequency band (incident band $\sim 0.04 \mathrm{~Hz}-0.4 \mathrm{~Hz}$ ), and a low frequency band (infragravity band, $\sim 0.004 \mathrm{~Hz}$ 0.04Hz). During extreme wave conditions, the wave runup can exceed $10 \mathrm{~m}$ (see Figure 3; Poate et al. 2016). It 
is thus a key parameter for the design of coastal structures and the prediction of overtopping volumes during storm events. Given the strongly nonlinear nature of the wave breaking process, the transition from undular bore to wave runup and the collision between uprush and backwash, analytical solutions have been derived for simplified cases only (e.g. Carrier and Greenspan, 1957) and the cost of numerical simulations capable of representing such processes is often prohibitive for large-scale studies. Significant advances for the prediction of wave runup in natural environments stem from empirical approaches conducted either in laboratory (Hunt 1959; Van der Meer and Stam 1992) or in the field (see Stockdon et al. 2006 for a description of major runup field experiments conducted between 1982 and 1997). These studies have shown that the wave runup mostly depends on the wave height $(\mathrm{H})$, the wavelength $(\mathrm{L})$ and the foreshore slope $(\beta)$ (see Section 4.1.3 and Table 1 for a list of wave runup formulation). Since the wavelength scales with the square of the wave period in deep water, the wave period has actually a larger influence than the wave height on the runup. However, the range of wave period at a given site is usually lower than the range of wave heights and this latter often display stronger correlations with the wave runup (Poate et al. 2016; Dodet et al. 2018). Several studies investigated more closely the spectral distribution of the wave energy in the swash zone and revealed that the energy in the incident band could be saturated in dissipative environments, such as high-energy low-sloping beaches, so that infragravity wave energy was dominant (Ruessink et al. 1998). In order to investigate the impact of the foreshore slope on the wave runup, some authors took advantage of the strong alongshore variability of sandy beaches (Ruggiero et al. 2004) or the large tidal range that modifies the foreshore morphology felt by the waves (Suanez et al. 2015), or carried out inter-field comparisons (Stockdon et al. 2006). These studies show a significant impact of the foreshore slope on the runup for reflective conditions and a lesser or nonexistent impact for high energy dissipative environments.

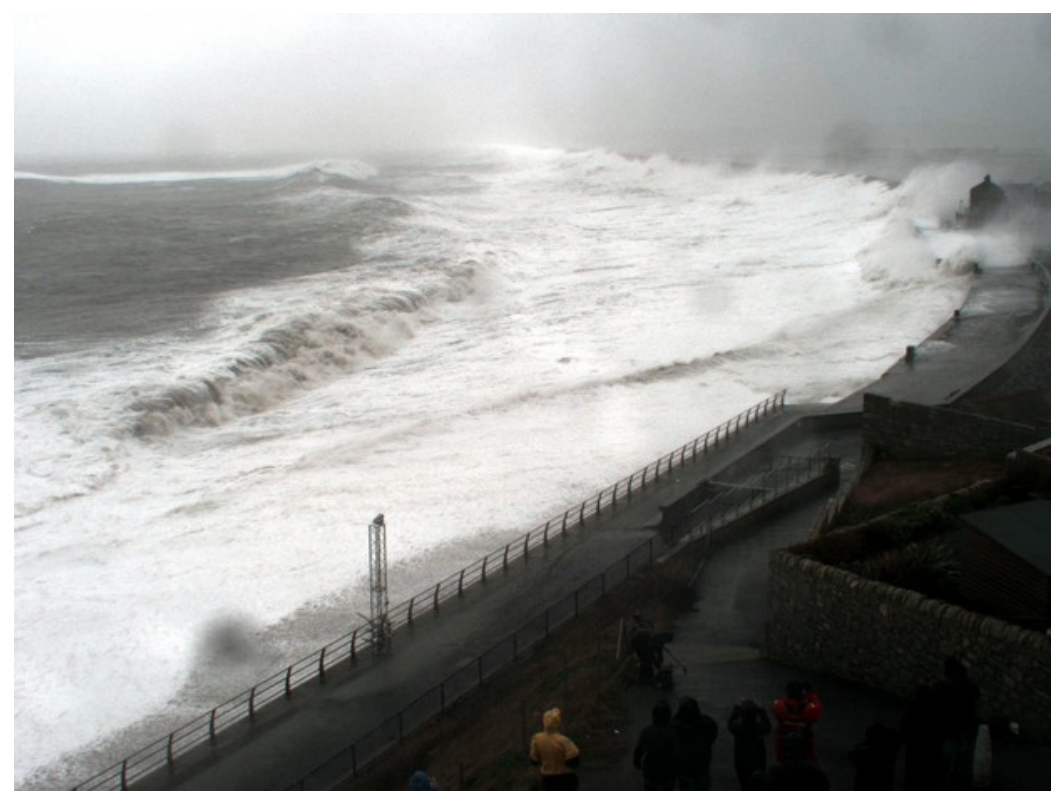

Fig.3 Example of coastal defence overtopping at Chesil beach, UK, caused by extreme swash events exceeding $10 \mathrm{~m}$ (see Poate et al. 2016) during Petra storm on February 5, 2014 (credits: Tim Poate)

In this section, we have seen that wave-induced coastal processes have a significant impact on coastal sea level. All these processes are largely controlled by offshore wave conditions. Therefore, given the strong variability of 
the offshore wave climate at various timescales (seasonal, inter-annual, decadal) and its potential long-term evolution in the context of climate change, it is particularly important to better understand past and future changes in wave conditions and how these changes will translate in terms of coastal sea level.

\section{Characterization and variability of offshore wave conditions}

Since the first evidence of long-term changes in significant wave height measured by the Sevenstones Lightship wave recorder $25 \mathrm{~km}$ off Cornwall Land's End (UK) (Carter and Draper, 1988), significant progress has been achieved on our comprehension of past and future evolution of the wave climate. Part of this progress can be attributed to the deployment and maintenance of large scale buoy networks, the development of numerical models, and the advent of satellite Earth Observation programmes. In this section, we first describe the different methods that are used to characterize offshore wave conditions. Then, we present the current state of the art regarding past and future evolution of the wave climate at global scale, based on the IPCC 5th Assessment Report (AR5; chapter 3, Rhein et al. 2013 and chapter 13, Church et al. 2013) and the Special Report on Managing the Risks of Extreme Events and Disasters to Advance Climate Change Adaptation (SREX; chapter

245 3, Seneviratne et al. 2012) as well as more recent findings published since AR5.

\subsection{In-situ and remote sensing observations of offshore wave conditions}

Wave measurements started with visual observations from the coast using a wind sea and swell separation method and estimations of wave heights and periods (Gain 1923, Munk and Traylor 1947). Such visual observation programs continue for offshore ship-based observations (e.g. Gulev et al. 2003), providing the longer time series of wave measurements (Gulev and Grigorieva, 2004). Offshore of the surf zone and in regions where currents are under $1 \mathrm{~m} / \mathrm{s}$, the most common source of wave measurements are moored surfacefollowing buoys based on accelerometers (Longuet-Higgins et al. 1963, Allender et al. 1989) or GPS velocity measurements (Herbers et al. 2012). Although not coordinated under a single international program, the collection of wave buoy data has been facilitated by the Oceansites program (Send et al. 2009), as well as various efforts associated to the Global Ocean Observing System (GOOS) and the Copernicus Marine Environment Monitoring System (CMEMS). The actual response of the buoy to the water motion depends on the hull shape and sensor mounting (Jensen et al. 2015, Guimaraes et al. 2018). Where currents are strong, ADCPs are interesting alternatives to measure both currents and waves (Herbers and Lentz 2010), and drifting surface buoys can also provide interesting information either with dedicated buoys (Thomson et al. 2012), or with motion packages added on drifters from the global Surface Velocity Program (Lumpkin et al. 2016). In that context, in-situ wave measurements are today provided by hundreds of wave buoy moored in both deep or coastal waters (typically in 15-100 m depth), with most time series extending over 20 to 40 years (e.g. US National Data Buoy Center, https://www.ndbc.noaa.gov/). These measurements cannot give the detailed wave information needed to estimate coastal sea levels, in particular over complex shorelines due to wave evolution outside of the surf zone, mostly due to refraction (Munk and Traylor 1947, Magne et al. 2007) and bottom friction (e.g. Ardhuin et al. 2003, Roland and Ardhuin 2014). Also, buoys do not measure the full directional spectrum but moments of its distribution, that lead to important uncertainties when waves are propagated to the coast (e.g. Crosby et al. 2017). 
A more complete spatial coverage of ocean waves is provided by satellite remote sensing, as illustrated in Figure 4. Nowadays, satellites provides most of the background data for wave climatologies and detection of trends. Satellite altimeters, particularly, give an uninterrupted record of significant wave height since the launch of ERS-1 in 1991. Additional information on the sea state, in particular wave periods that are critical for estimating wave-induced water levels at the coast, can be obtained with other satellite remote sensing techniques. In particular, ERS-1, ERS-2, Envisat and the Sentinel 1 constellation carry Synthetic Aperture Radars (SARs) that are operated in "wave mode" over most of the oceans (Hasselmann et al. 2012). SAR provide radar images from which the height, period and direction of swells can be estimated, provided that their wavelength is long enough, typically more than $200 \mathrm{~m}$ depending on their direction and on the wind speed (Kerbaol et al. 1998). Both altimeter $H s$ and SAR-derived swell partitions are assimilated into the CMEMS/Meteo-France operational global model (Aouf et al. 2006), which today provides the most accurate forecasts of wave heights (Bidlot, 2017), with the swell assimilation impact strongest in the Pacific ocean.

(A)

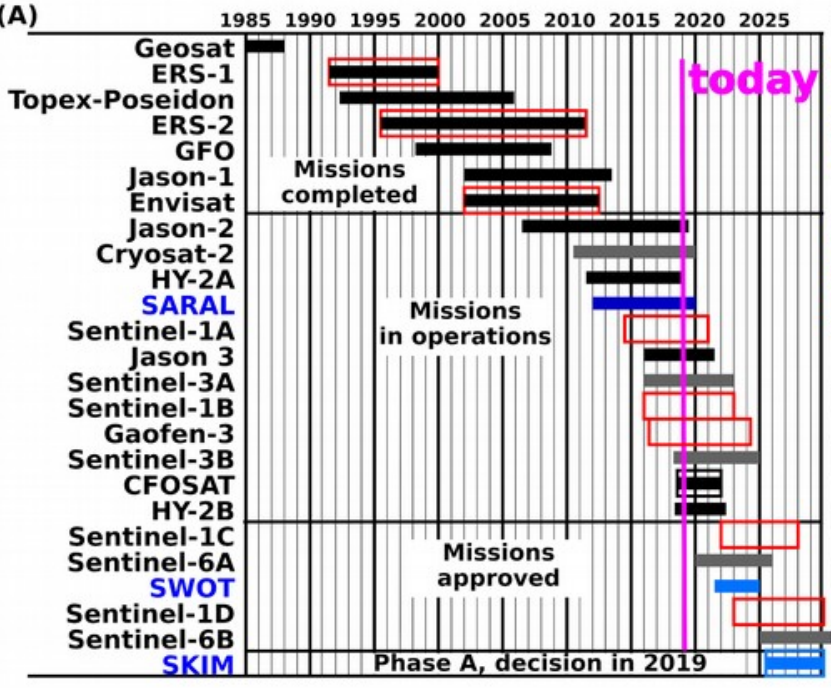

(B)

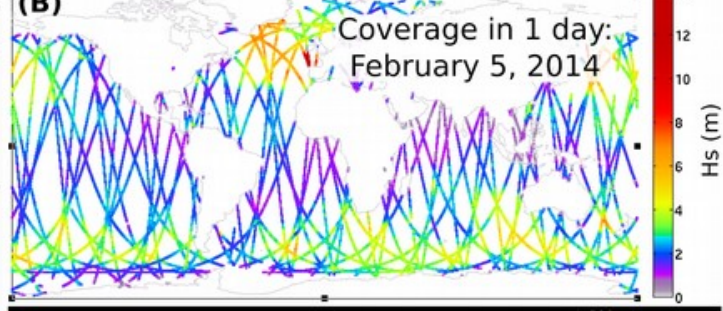

Fig.4 (a) Time coverage of satellite missions from 1985 to 2030, including nadir and near-nadir altimeters (solid bars) missions monitoring ocean wave spectra (open box) using C-band Synthetic Aperture Radars (red), and real aperture radars in Ku-band (black) or Ka-band (blue). The light grey bars correspond to altimeters using Delay-Doppler processing. (b) example of 1-day coverage for Hs measurements with four satellite altimeters (c) snapshot of "fireworks", showing peak periods, and heights of swell partitions derived from Sentinel-1A and

Sentinel-1B wave mode data

\subsection{Regional modelling of offshore wave conditions}

Given the difficulty to monitor waves over large spatial and temporal scales, numerical models are important tools, often combined with in situ measurements and remote sensing. A wide range of numerical techniques exist, each adapted to particular scales and physical processes to be accounted for (see Ardhuin and Orfila, 2018 for a recent review). As long as time resolution shorter than the wave group scale (a few minutes) is not needed, the flow, water level and wave motion can be separated, and the waves are efficiently solved with spectral wave models that are generally phase-averaged (e.g. the WAVEWATCH III Development Group 2016) and that may also include a bispectrum evolution for taking into account non-local nonlinear effects (Herbers and Burton 


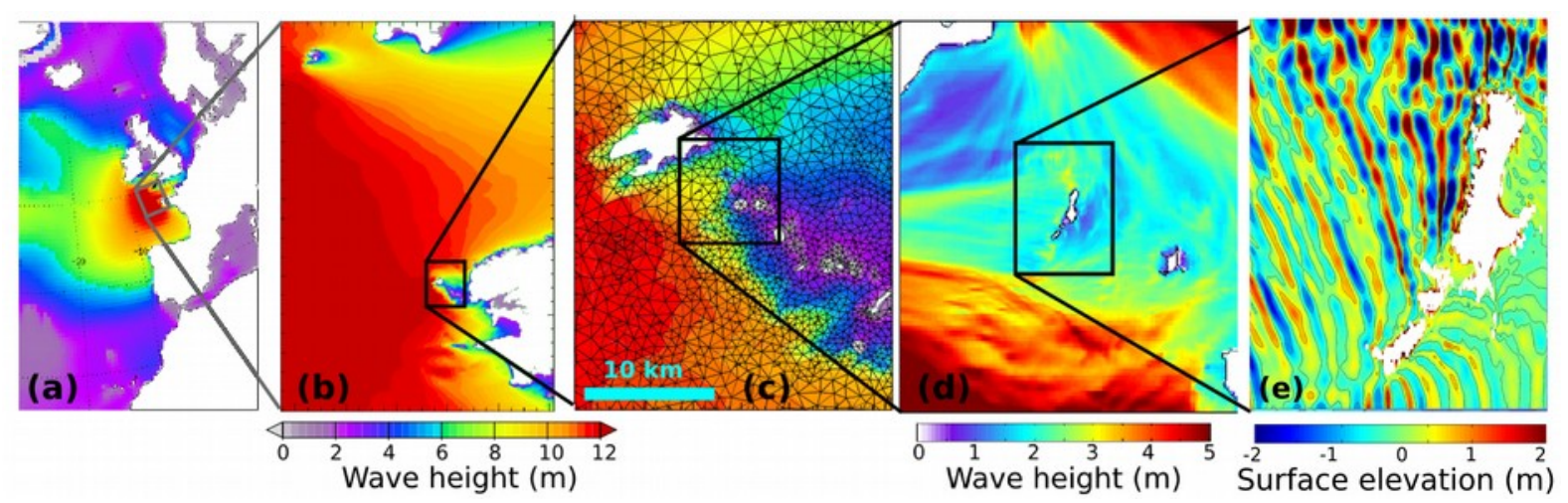

Fig.5 Example of multiple scales wave modelling. (a,b,c) phase-averaged wave model (WAVEWATCH III, the WAVEWATCH III Development Group, 2016), (d) wave-group resolving model (X-Beach, Roelvink et al. 2018), and (e) phase-resolving wave model (SWASH, Zijlema et al. 2011), here applied at Banneg Island, France.

Numerical models can provide good wave prediction, but are computationally time consuming. Meta-models (also called "response surface”, "surrogate model”, “model emulators”, "proxy models”) provide an alternative approach to tackle the computation time issue. They are based on the definition of a statistical relationship between the inputs (X, called the "predictor") and the output (Y, called the "predictant"). Such fast running model allows for instance performing sensitivity analysis, exploring the effect of uncertainties in $\mathrm{X}$ on the $\mathrm{Y}$ results, or performing ensemble simulations. From the literature review, wave meta-models can be divided into two categories (statistical downscaling (SD) and hybrid (H) models), the first one being the one used when investigating waves at a regional scale. Local waves resulting from the regional meteorology over a few days scale (Camus et al. 2014a), the SD models relate a large-scale predictor (most of the time the sea level pressure fields or its squared gradient) with a local predictand (multivariate wave conditions, e.g. wave height, period and direction). They require atmospheric and sea-state databases. One of the key points in statistical downscaling is to reduce the dimension of the inputs, i.e, here the mean sea-level pressure (or its gradient), which has very high dimension (number of grid points times the number of time steps). This reduction is often based on principal component analysis. Then, two types of approaches have been pursued. In a first one, the SD model is defined as a linear combination of the most important PCs of the predictor defined specifically for the analyzed target location (see e.g. Camus et al. 2014a). In the second one, the SD model estimates the predictant based on the occurrence of weather types (see e.g. Camus et al. 2014b, Laugel et al. 2014; Perez et al. 2015; Rueda et al. 2016). These weather types are obtained by clustering methods (e.g. K-means), initialized by a maximum dissimilarity algorithm. In many studies a typical number of 100 weather types is used. Then a regression model is built between these weather types and the wave conditions. At the end, a statistical model is built allowing emulating the wave conditions with a negligible computation time. However, although revealing the dominant modes of wave climate variability and trends, the statistical downscaling methods still faces issues to predict extremes at high frequency (e.g. hour scale). It should be noted that statistical downscaling models aiming at predicting cyclone-induced wave conditions rely on the cyclone characteristics rather than on spatio-temporal meteorological fields (see e.g. Jia and Taflanidis, 2013; Rohmer et al. 2016). 
3.3 Past changes in wave conditions during the 20th century

335 Buoy data and Voluntary Observing Ship (VOS) reports indicate statistically significant positive Hs trends during the second half of the 20th century over the North-Atlantic, north of $45^{\circ} \mathrm{N}$, and over the central to eastern mid-latitude North Pacific with typical trends of up to $2 \mathrm{~cm}$ per year, as shown in Figure 6a (Gulev and Grigorieva, 2006, Ruggiero et al. 2010). However, these measurements suffer from limited spatial coverage, particularly in the Southern Ocean. In addition, some of the trends computed from the North Pacific buoy data

340 were introduced by modifications of the measurement techniques (Gemmrich et al. 2011). For these reasons, satellite altimeter observations available since the mid-1980's provide extremely valuable data source for investigating wave height variability at global scale. Using an extensive altimetry database Young and Ribal (2019) found positive trends (up to $0.5 \mathrm{~cm}$ per year) for the mean annual Hs in some part of the Southern Ocean and negative trends in the central part of the North Pacific, with a global low level of statistical significance

345 (Figure 6c). They also obtained stronger positive trends (up to $1 \mathrm{~cm}$ per year) for the 99th Hs percentile in the Southern Ocean, North Atlantic and North West Pacific. Given the short time period covered by the data (19852018) and the strong link between variations in waves and internal climate variability, it is yet difficult to determine whether these results reflect long-term $H s$ trends or are part of decadal oscillation. The differences observed between the trends computed over the period 1985-2018 from satellite altimetry and the ones computed over the period 1957-2002 from observations and model results (compare Figure 6 a,b and c) also illustrate how the internal atmospheric variability may impact the Hs trends computed over a few decades. 

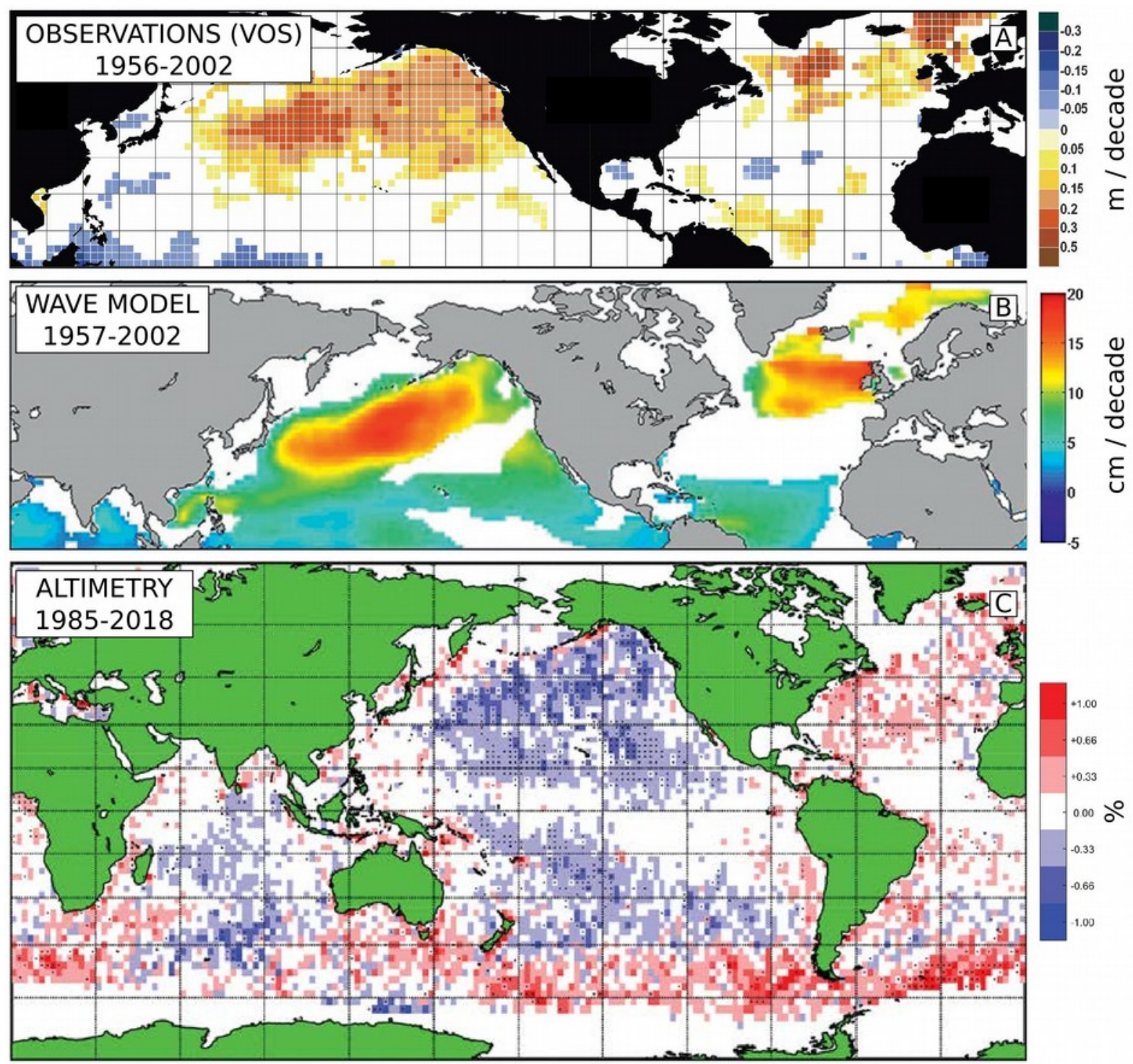

Fig.6 Trends in significant wave height estimated from (a) Visual Observing Ship observations over the period

355 1956-2002 (Gulev and Grigorieva, 2006); (b) numerical wave model hindcast over the period 1957-2002 (Semedo et al, 2010): (c) satellite altimetry over the period 1985-2018 (Young and Ribal, 2019). In each of these studies, values which are not statistically significant are either not shown (a and b) or not marked with black dots (c). Adapted from Gulev and Grigorieva (2004), Semedo et al. (2010) and Young and Ribal (2018).

360 Numerical wave hindcasts forced by General Circulation Models (GCM) or Regional Climate Model (RCM) reanalysis offer an additional alternative to study wave climate variability over a longer time period with a high resolution and global coverage, even though temporal inhomogeneity in the reanalysis data limit the confidence in the model results for long-term trends analysis (e.g. Stopa et al. 2019). A 45-year (1957-2002) hindcast forced by the ERA-40 reanalysis from the European Centre for Medium-Range Weather Forecasts (ECMWF) revealed positive $H s$ trends in the North Atlantic and North Pacific similar to the one obtained from in-situ measurements (Semedo et al. 2010, Figure 6b). Hemer (2010) obtained positive trends across most of the Southern Hemisphere using a Corrected ERA-40 reanalysis and showed that winter $H s$ was strongly correlated with the SAM They also found an anti-clockwise rotation of wave direction with the southward intensification 
of the Southern Ocean storm belt associated with the SAM In the North-Atlantic, Dodet et al. (2010) found positive Hs trends (up to $15 \mathrm{~cm} /$ decade) north of $40^{\circ} \mathrm{N}$ and clockwise trends (up to $1 \%$ decade) in mean wave direction south of $45^{\circ} \mathrm{N}$ during the period 1953-2009. They related these changes to a strengthening and northward shift of mid-latitude storms associated with changes in the North Atlantic Oscillation that shifted from a negative phase in the 1960's to a positive phase in the 1990's. These results are consistent with the 19582002 wave hindcast of Charles et al. (2012). Bertin et al. (2013) performed a 109-year numerical wave hindcasts

375 for the North Atlantic and found significant upward trends in yearly-mean Hs in the North-East Atlantic, reaching $10 \mathrm{~cm} /$ decade around $60^{\circ} \mathrm{N}$, despite any trends in NAO over the same period. This upward trend was explained by an upward trend in $10 \mathrm{~m}$ winds, observed both in atmospheric hindcast and in observations from VOS (Gulev et al. 2003). More recently, Castelle et al. (2018) performed a wavelet analysis in a 69-year (19492017) wave hindcast in the North-East Atlantic and found an increase in Hs variability starting in the 1990's,

380 that is also observed in the pressure based index. In the Arctic Ocean, reduction in summer sea ice extent resulted in enhanced wave activity due to increased fetch area and longer duration of the open water season (Overeem et al. 2011; Stopa et al. 2016).

\subsection{Projected changes for the end of the 21st century}

385 Given the usually coarse resolution (typically $250 \mathrm{~km}$ ) of the atmospheric component of global coupled atmosphere-ocean GCM, global wave climate projections usually require dynamical (Wang and Swail, 2006) or statistical (Camus et al. 2017) downscaling approaches to increase the resolution of the forcing wind fields. Hemer et al. (2013a) analyzed the results of an ensemble of four dynamical and one statistical wave models developed as part of the Coordinated Ocean Wave Climate Project (COWCLIP) and compared the averaged 390 multi-model wave parameters for the time-slice 2070-2100 with the ones for the time-slice 1979-2009 (Figure 7). They found a statistically significant decrease in the annual Hs for $25.8 \%$ of the global ocean area, and a statistically significant increase for $7.1 \%$ of the global ocean, predominantly in the Southern Ocean. These trends were more pronounced when focussing on the winter mean. The increase in wave activity in the Southern Ocean was shown to affect the wave period and wave direction in the other ocean basins, with a 395 clockwise rotation of the wave direction in the tropics and larger wave periods in the eastern Pacific, as a result of enhanced wave generation in the Southern Ocean and northward swell propagation. In the North-Atlantic and North-Pacific, a significant decrease in Hs and wave period is associated to weaker wind forcing projected in these regions. Wang et al. (2015) used a statistical model to derive project changes in Hs from changes in the sea-level pressure fields of 20 CMIP5 simulations. They obtained trend patterns similar to previous analysis, but also noted some differences with the results of studies based on CMIP3 GCM (Hemer et al. 2013a). For instance, they found a much more extensive Hs increase in the tropical South Pacific, and an opposite Hs trend (increasing instead of decreasing) in the tropical South Atlantic, compared to Hemer et al. (2013a). Mentaschi et al. (2017) computed the projected changes in wave energy fluxes (integrating both Hs and the wave period) from the results of a wave model forced by an ensemble of five CMIP5 GCM models. They found a significant increase up to $30 \%$ in the 100 year return level for the majority of the coastal areas of the southern temperate zone and significant negative trend in large areas of the northern hemisphere. They explained these trends in extreme wave energy fluxes (WEF) by the intensification of teleconnection patterns such as the Arctic Oscillation (AO), the El-Nino Southern Oscillation (ENSO) and the NAO Casas-Prat et al. (2018) investigated 
the future wave projections in the Arctic using an unstructured spherical grid wave model forced with the wind fields and ice-concentration of five CMIP5 GCM models. They found that by the end of the 21st century the wave climate in the Arctic region will be significantly different compared to the current climate due to ice retreat yielding new open water areas for wave generation. In particular, their ensemble projected mean Hs changes to reach $1.75 \mathrm{~m}$ by the end of the 21st century in newly open water. In the historical open water areas, the ensemble average projected some significant increases (up to 15\%) in the Barents Sea, which can be related

415 to the local increase in surface wind.
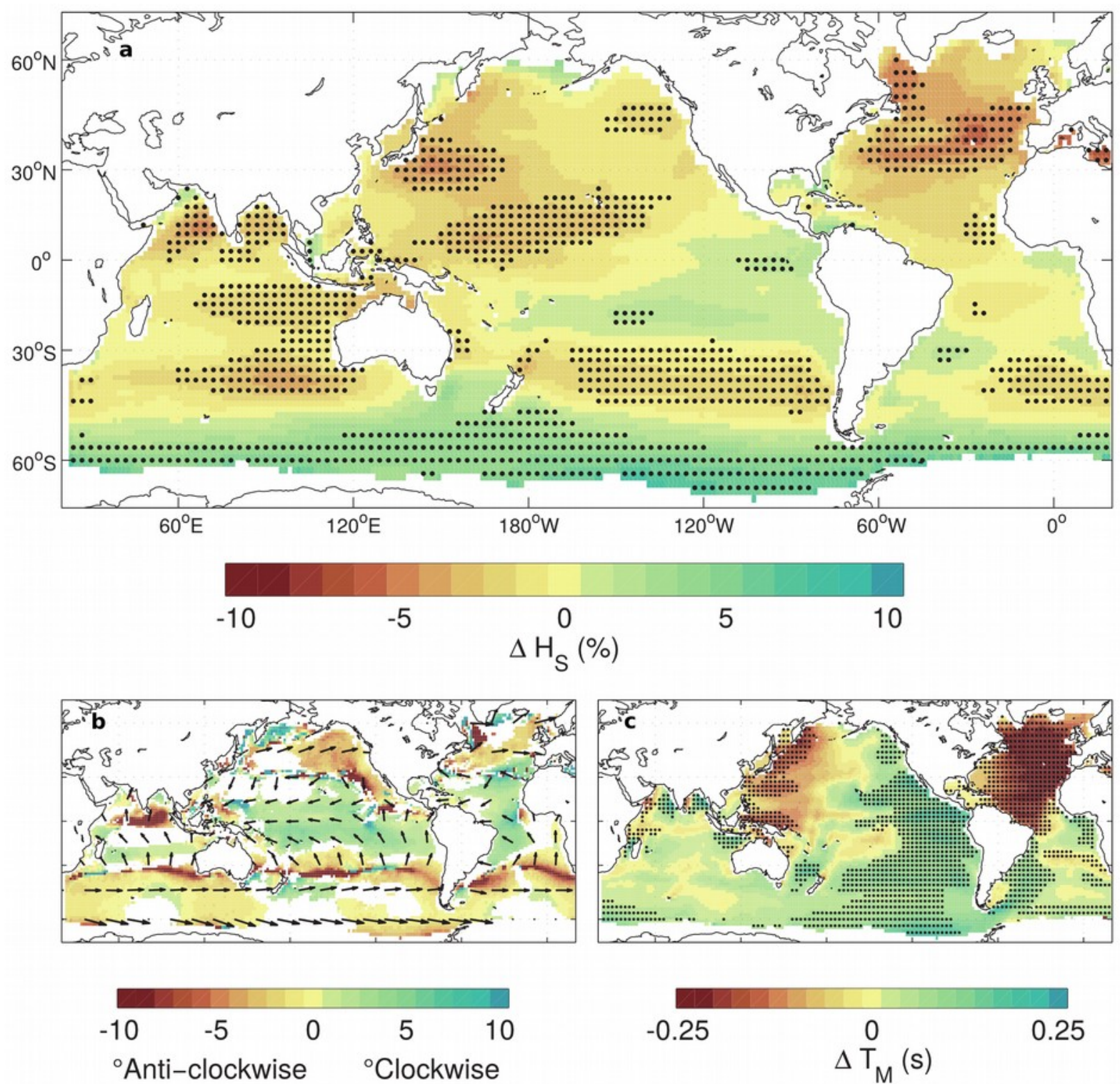

$-0.25$

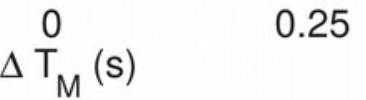

Fig.7 Projected changes in wind-wave conditions ( 2075-2100 compared with 1980-2009) derived from the

420 Coordinated Ocean Wave Climate Projection (COWCLIP) Project (Hemer et al. 2013a). (a) Percentage difference in annual mean Hs. (b) As for (a), but displaying absolute changes in mean wave direction, with positive values representing projected clockwise rotation relative to displayed vectors, and colours shown only where ensemble members agree on the sign of change. (c) As for (a), but displaying absolute changes in mean 
wave period. The symbol $\sim$ is used to indicate that the reference periods differ slightly for the various model studies considered. Adapted from Church et al. (2013)

In summary, offshore wave conditions show strong spatial and temporal variability, which can be related to large-scale patterns in the atmospheric circulation. Although most available wave data are too short or overly inhomogeneous to clearly depict past long-term trends, most studies agree on significant positive Hs rends of the order of $\sim 1 \mathrm{~cm} /$ year in the North Atlantic and Southern Ocean. In contrast model projections for the end of the century tend to agree on a significant decrease in Hs in the North-Atlantic, and a significant increase in the Southern Hemisphere, but show contrasting results in other ocean basins such as the South Atlantic, the Indian Ocean or the North Pacific (Morim et al. 2018). In the following section, we will see how such changes may impact coastal sea level and add to ocean dynamic sea level rise.

\section{Wave impacts on coastal sea level}

Measuring ocean properties in the nearshore environment is a challenging task. Contrary to deep water environments, the nearshore bottom topography play a fundamental role in the ocean dynamics, through refraction, diffraction, frictional, shoaling, breaking and resonant processes. Hence, the observed variability of most physical ocean parameters (wave height, sea level, currents) cannot be investigated without knowledge on the bottom topography, which is hardly available and may evolve rapidly. Also, the strong gradients in the bottom topography, currents and wave properties, which characterize the nearshore zone, often preclude the application of large scale remote sensing techniques and coarse resolution modelling strategy. Finally, the strong wave energy dissipation that occur when wave break in the nearshore (see Section 2) make the surfzone a very dynamic area with strong currents and rapid topographic changes, where long-term deployment of in-situ measurements is very complicated. For these reasons, our knowledge on coastal sea level mostly rely on a few tide gauge time-series sheltered from the effect of wave and is therefore very limited compared to our knowledge on offshore sea level changes. In this section, we present the current techniques used to measure and model nearshore topography, wave and sea level. Then we discuss the impact of waves on coastal sea level based on recently published studies.

4.1 Topography, waves and sea level in the nearshore

\subsubsection{Observation techniques}

Important nearshore observation programs have been developed in Australia, Europe, or in the United States,

with long-term monitoring of beach topography, nearshore wave conditions and water level that now extend over 30 years, but only at a few dedicated locations. The US Army Corps of Engineers Field Research Facility, located in Duck, North Carolina, is one of these sites with a continuous detailed monitoring of offshore and nearshore directional wave spectra, beach profiles and daytime video monitoring of the nearshore, and intensive process studies (Birkemeier et al. 1996; Holman and Stanley, 2007). The Petten dike in the Netherlands (Wenneker et al. 2016), Narrabeen beach in Australia (Turner et al. 2016) or Truc Vert beach in France (Castelle et al. 2014) are other examples of coastal locations dedicated to long-term monitoring survey. At these sites, observations of sea level right at the shoreline have been combined with measurements of waves and nearshore topography to produce empirical parameterizations (see Section 4.1.3), suggesting that observing surf 
zone topography and waves outside of the surf zone could be a first step to extrapolate regional scale storm surge levels all the way to sea levels right at the coast.

Close to the shoreline and across the surf zone, pressure-based systems have been developed (Barber et al. 1946, Munk et al. 1963) and are still widely used to measure the wave spectrum, giving the distribution of the surface elevation variance as a function of frequency, with recent improvements to correct for non-linearities in the transformation from bottom pressure to surface elevation (Bonneton et al. 2017). Pressure is often combined with velocity measurements to provide a measurement of wave propagation direction as well as currents (e.g. Thornton and Guza 1986). Other instruments used routinely from structures include run-up gauges (Wenneker et al. 2016) and shore-based video systems (Holman and Haller, 2013). With the progress made on estimating variables from video imagery, such as wave height, sea level and runup, and morphology, this technique offers now access to an unequalled high frequency (hourly) and long-term description of the nearshore dynamics (Pianca et al. 2015; Almar et al. 2017; Brodie et al. 2018) including bathymetry (Holman et al. 2013; Bergsma and Almar, 2018) and sea level (Abessolo Ondoa et al. 2019). The installation of shore-based video stations to monitor the nearshore is increasingly used due to their possibilities and low cost. Combining these video techniques with the use of Unmanned Aerial Vehicle (UAV) has also greatly enlarged the scope of application of these methods (e.g. Turner and Harley, 2016; Matsuba et al. 2018). Although video is limited to daytime monitoring, the development of lidar technology is expanding the possibilities of shore-based remote sensing (Blenkinsopp et al. 2010; Almeida et al. 2015, Brodie et al. 2015) and now offers an attractive alternative to monitor high frequency topography and runup or more recently, the detailed geometric properties of waves in the surfzone (Martins et al. 2018). First long-term deployments are being conducted (e.g. at Narrabeen, 485 Australia) and should provide soon new insights in the quantification of multi-scale runup dynamics and flooding events (Almeida et al. 2018). Combining measurements from shore-based lidars and from tide gauges might allow to separate observed wave setup and runup from offshore sea level variability. However, all these measurements are very localized and give a very partial view of the complex spatial patterns in waves and associated water levels. Figure 8 shows several instruments used to measure nearshore parameters.
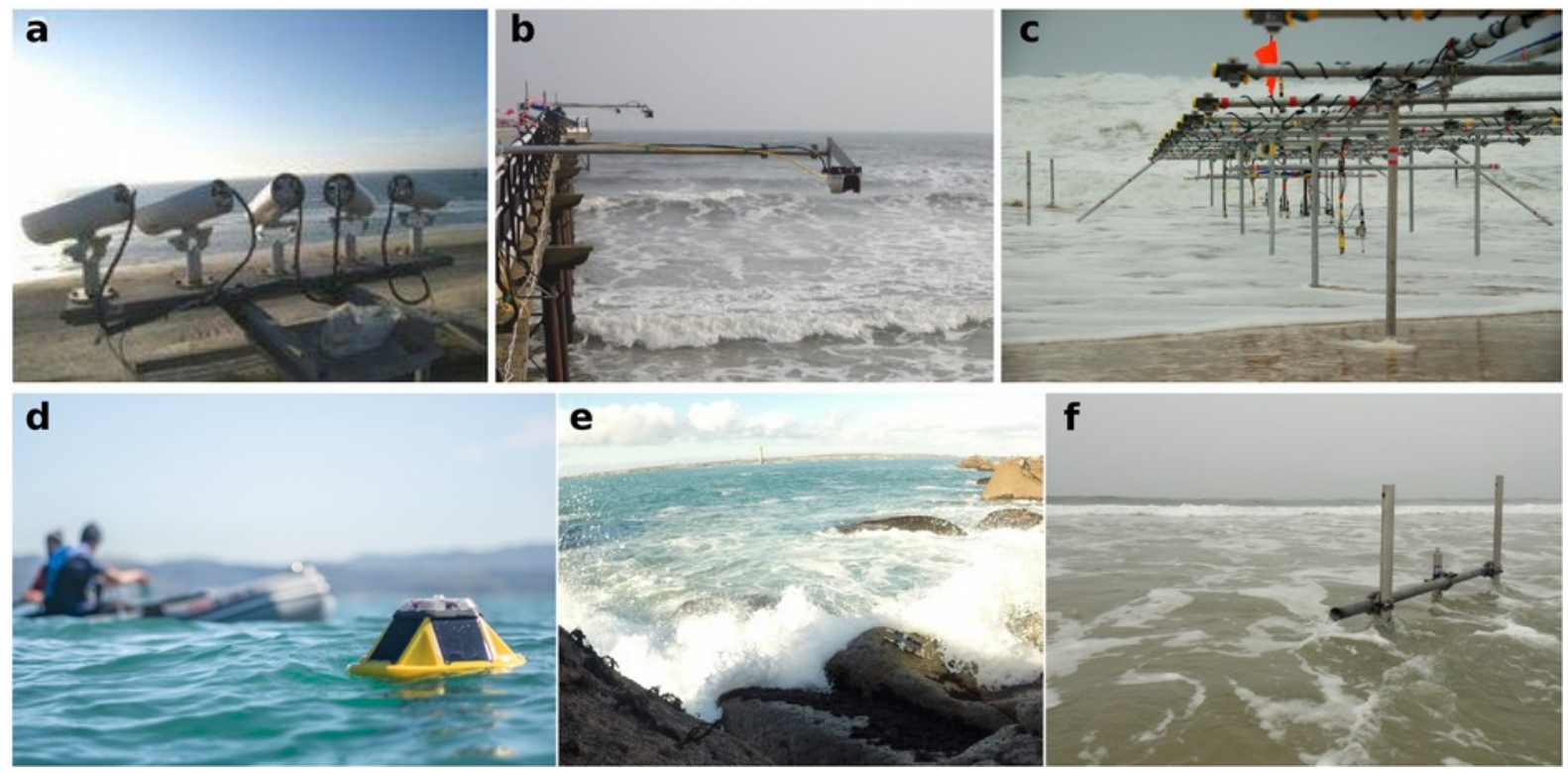
Fig.8 a) Video camera system overlooking Biscarosse beach, France (Marchesiello et al. 2015); b) LIDAR scanner array fixed along a pier at Saltburn beach, UK (Martins et al. 2017); c) array of ultrasonic sensors measuring swash and bed elevations at Truc Vert beach, France (Masselink et al. 2009, credits: Tim Scott); d) wave buoy Spotter; e) pressure sensors installed on the rocky cliffs of Banneg Island, France (Dodet et al. 2018); f) PUV system (pressure and current-meter) partially immersed on the ebb shoal of the Obidos lagoon, Portugal (Bruneau et al. 2011)

\subsubsection{Numerical models}

500 Spectral phase-averaged models are typically only limited by their poor representation of diffraction effects (e.g. Holthuijsen et al. 2003), which are typically negligible on natural topographies (e.g. Figure 9 and Magne et al. 2007). In small areas, the effect of local winds may be neglected and backward ray tracing can be a very efficient linear model (O’Reilly and Guza 1993, Crosby et al. 2017). Phase resolving models can also be used to better represent steep topographies and associated diffraction, as well as non-linear shoaling effects, however, in their time-stepping version they can be prohibitively expensive in computation time for regions larger than about $10 \mathrm{~km}$ and time scales beyond a few hours. However, a great advantage of such models is that they solve the full flow, including water level variations and currents, allowing the representation of rapid couplings for example in the swash zone, including inundation (e.g. Chen et al. 2003, Zijlema et al. 2011, Torres-Freyermuth et al. 2013).
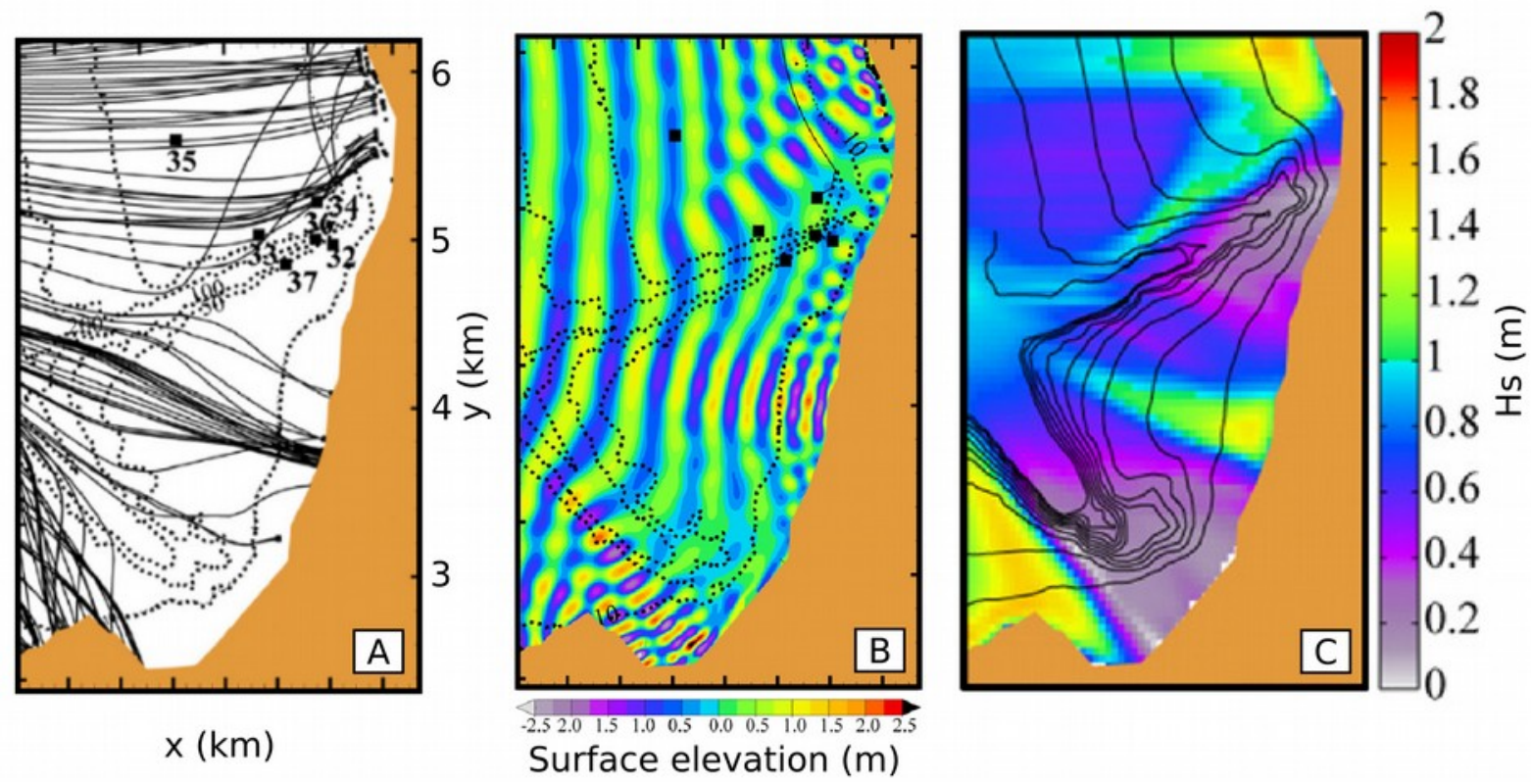

Fig.9 Different representations of wave propagation over the Scripps-La Jolla submarine canyons. (a) Wave

rays for $15 \mathrm{~s}$ with a constant offshore direction from the West and an offshore spacing of $20 \mathrm{~m}$. (b) Solution of the mild slope equation for $1 \mathrm{~m}$ amplitude $15 \mathrm{~s}$ monochromatic swells, with a phase-resolving model. (c) Significant wave height computed for $15 \mathrm{~s}$ swells from the West with a phase-average spectral model. Adapted from WISE Group (2007) 
520 Ocean circulation models (either based on the shallow water or the primitive equations) can be forced by phaseaveraged forces to represent the wave effect on the mean sea level, the set-up. This approach is generally successful except in very shallow water (Apotsos et al. 2007). Numerous coupled wave-current models have been developed in the last decade with some applications to coastal water levels (e.g. Walstra et al. 2000; Ozer et al. 2000; Kumar et al. 2012; Bennis et al. 2014; Stockdon et al. 2014; Cohn and Ruggiero, 2016; Guerin et al.

525 2018). For depth-integrated motions, waves contribute to a horizontal force, that is usually represented by the divergence of a horizontal radiation stress tensor (Longuet-Higgins and Stewart 1964, Smith 2006). When vertical profiles of the current are considered, it is most convenient to write the equations for the flow momentum only (McWilliams et al. 2004; Ardhuin et al. 2008; Suzuki and Fox-Kemper 2016).

530 The effect of infragravity waves has for long remained unaccounted for in wave-current models. However, the devastating impact of several hurricanes on the sandy coasts of Florida in 2004 has triggered the development of a new modelling approach to simulate water level changes during storms including the effect of IG waves. The XBeach modelling system (Roelvink et al. 2009) uses this so called "surfbeat" approach and couples a depthintegrated flow model with a spectral wave model, which represents the short wave groups. IG waves can also

535 be represented using phase-resolving models (e.g. Zijlema et al. 2011; Bonneton et al. 2011), although the large associated computational time limits such approach to domains a few km-large at maximum.

\subsubsection{Empirical models}

Wave setup and runup cannot yet be modelled at large spatial scales (regional to global) with numerical

540 hydrodynamic models or over the long periods needed to study, for instance, their contribution to water level extremes (statistically) and their evolution under climate change, as they would need high-resolution mesh, knowledge of the full incident wave spectra and of nearshore morphology. To overcome these difficulties, empirical parameterizations have been developed based on observations collected during field or laboratory experiments to estimate wave setup and runup for natural beaches and artificial structures.

545 Most studies have shown that the wave setup and the wave runup mostly depends on the offshore wave height $\left(H_{0}\right)$, the offshore wavelength $\left(L_{0}\right)$ and the foreshore slope $(\tan \beta \sim \beta)$, and can be expressed as a function of the Iribarren number $=\tan \left(\mathrm{H}_{0} / \mathrm{L}_{0}\right)^{-0.5}$ (Iribarren and Nogales, 1949), also known as the surf-similarity parameter (Battjes, 1974). The most common scaling for runup is that of Hunt (1959), where runup is proportional to $\xi_{0} \mathrm{H}_{0}$, which is equal to $\tan \beta\left(H_{0} L_{0}\right)^{0.5}$. A non-exhaustive list of the most commonly used empirical formulations of

550 setup and runup can be found in Tables 1 and 2 respectively, and in the references therein. A list of empirical swash formulations can be found in Passarella et al. 2018. Note that the definition of the beach slope is not straightforward for complex profiles (e.g. concave profiles, presence of sandbars, rocky cliffs time-evolving bathymetry), but on natural beaches, the value of $\beta$ is often taken as the foreshore slope, in the region covered by the swash (Stockdon et al. 2006). The foreshore beach slope can substantially vary in time and alongshore,

555 and has been poorly measured so far. As the dependence of runup to the coastal morphology is stronger for nondissipative beaches, several empirical formulations for runup were also derived without a dependence to the beach slope, to be applicable to dissipative beaches only (e.g. Mase (1989), Holman and Sallenger (1985), Powell (1990), Nielsen and Hanslow (1991), Stockdon et al. (2006), Roberts et al. (2010), Table 2). 
Existing wave setup, swash or runup formulations were extensively tested (e.g. Atkinson et al. 2017; Di Luccio

et al. 2018; Senechal et al. 2011; Vousdoukas et al. 2012; Cohn and Ruggiero, 2016; Diaz-Sanchez et al. 2014; Stockdon et al. 2014; Passarella et al. 2018; Ji et al. 2018; Pullen et al. 2007; Power et al. 2019). Although most of these formulae have significant skills, the scatter between predicted and observed setup or runup can be substantial. This could be due to second order processes (e.g. edge waves, variability of the beach slope, nearshore morphological control on runup that is not captured when only accounting for the beach slope) that are not represented by the formulations’ predictors (e.g. Diaz-Sanchez et al. 2014). In addition, empirical setup and runup formulations have been calibrated and / or validated with short observational time series, and Power et al. 2019 showed that they are prone to significant errors when applied outside the range of conditions over which they have been calibrated. Finally, empirical setup and runup formulations have mostly been developed for natural sandy beaches, which are among the most vulnerable environments to sea level changes (Wong et al.

570 2014) and cover a large fraction of the world's coast (Luijendijk et al. 2018). However, wave setup can exist in other coastal environments such as semi-enclosed bays, harbors (Thompson et Hamon 1980), rocky cliffs (Dodet et al. 2018) or steep-shelf small islands with fringing reefs (see e.g. Merrifield et al. 2014). Some processes that may be negligible for sandy beaches, may dominate in such environments. Recent experiments conducted on gravel beaches (Poate et al. 2016) and rocky cliffs (Dodet et al. 2018) have revealed the significant role of beach grain size, bottom roughness and water infiltration within fractured bedrock on the wave runup propagation. Therefore, research efforts are still actively on-going to improve existing formulations for setup, swash and runup (e.g. Atkinson et al. 2017; Power et al. 2019; Ji et al. 2018; Passarella et al. 2018) and to cover other coastal environments including structures (e.g. van der meer, 1992; Pullen et al. 2007) and gravel beaches (e.g. Poate et al. 2016).

\begin{tabular}{|c|c|c|}
\hline Reference & Empirical equation & Applicability range \\
\hline Guza and Thornton (1981) & $\eta=0.17 H_{s}$ & \\
\hline Holman and Sallenger (1985) & $\eta=0.46 \tan \beta \sqrt{H_{s} L_{0}}$ & $0.026<\beta<0.14$ \\
\hline Holman (1986) & $\eta=0.2 H_{s}$ & $0.07<\beta<0.2$ \\
\hline Hanslow and Nielsen (1992) & $\eta=0.048 \sqrt{\frac{H_{s}}{\sqrt{2}} L}$ & $0.03<\beta<0.16$ \\
\hline Komar (1998) & $\eta=0.45 \tan \beta \sqrt{H_{0} L_{0}}$ & $0.026<\beta<0.14$ \\
\hline Hedges and Mase (2004) & $\eta=0.34 H_{s}$ & $\xi_{s}<3$ \\
\hline Stockdon et al. (2006) & $\eta=0.35 \beta \sqrt{H_{0} L_{0}}$ & $\xi_{0}>0.3$ \\
\hline Stockdon et al. (2006) & $\eta=0.016 \sqrt{H_{0} L_{0}}$ & $\xi_{0}<0.3$ \\
\hline Atkinson et al. (2017) & $\eta=0.16 H_{s}$ & Model of models \\
\hline Ji et al. (2018) & $\eta=0.220 H_{s}^{0.629} L_{0}^{0.371}(\tan \beta)^{0.538}$ & $0.005<\beta<0.10$ \\
\hline
\end{tabular}




\begin{tabular}{|c|c|c|}
\hline Reference & Empirical equation & $\begin{array}{l}\text { Applicability } \\
\text { range }\end{array}$ \\
\hline Wassing (1957) & $R_{2 \%}=8 \tan \beta H_{s t}$ & $0.05<H / L<0.07$ \\
\hline Hunt (1959) & $R_{2 \%}=\tan \beta \sqrt{H_{0} L_{0}}$ & \\
\hline $\begin{array}{l}\text { Holman and } \\
\text { Sallenger (1985) }\end{array}$ & $R_{2 \%}=0.92 \tan \beta \sqrt{H_{s} L_{0}}$ & $0.026<\beta<0.14$ \\
\hline Holman (1986) & $R_{2 \%}=0.2 H_{s}+0.83 \tan \beta \sqrt{H_{s} L_{p}}$ & $0.07<\beta<0.2$ \\
\hline Mase (1989) & $R_{2 \%}=1.86 H_{0} \xi_{s}^{0.71}$ & $\begin{array}{l}0.03<\beta<0.2 \\
0.007 L_{0}<H_{0}\end{array}$ \\
\hline Powell (1990) & $R_{2 \%}=H_{s}\left[2.86-62.69\left(\frac{H_{s}}{L_{0}}\right)+443.29\left(\frac{H_{s}}{L_{0}}\right)^{2}\right]\left(\frac{-\ln 0.02}{4.2}\right)^{0.455}$ & $\begin{array}{l}\text { Gravel beaches, } \mathrm{H}_{\mathrm{s}} \\
<5 \mathrm{~m}\end{array}$ \\
\hline Nielsen and & $R_{2 \%}=S W L+1.98 * 0.042 \sqrt{H_{s} L_{0, s}}$ & $\beta<0.10$ \\
\hline Hanslow (1991) & $R_{2 \%}=S W L+1.85 * 0.52 \tan \beta \sqrt{H_{s} L_{0, s}}$ & $\beta \geq 0.10$ \\
\hline $\begin{array}{l}\text { Van der Meer } \\
\text { and Stam (1992) }\end{array}$ & $R_{2 \%}=1.5 \tan \beta \sqrt{H_{s t} L_{p}}$ & $0.5<\xi_{p}<2$ \\
\hline $\begin{array}{l}\text { Ruggiero et al. } \\
\text { (2001) }\end{array}$ & $R_{2 \%}=0.27 \sqrt{\beta H_{s} L_{p}}$ & $0.005<\beta<0.025$ \\
\hline $\begin{array}{l}\text { Hedges and Mase } \\
\text { (2004) }\end{array}$ & $R_{2 \%}=0.34 H_{s}+1.49 \tan \beta H_{s} L_{0}$ & $\xi_{s}<3$ \\
\hline $\begin{array}{l}\text { Stockdon et al. } \\
\text { (2006) }\end{array}$ & $R_{2 \%}=1.1\left[0.35 \beta \sqrt{H_{s} L_{p}}+0.5\left(H_{s} L_{p} \sqrt{0.563 \beta^{2}+0.004}\right)\right]$ & $\xi_{0}>0.3$ \\
\hline $\begin{array}{l}\text { Stockdon et al. } \\
\text { (2006) }\end{array}$ & $R_{2 \%}=0.043 \sqrt{H_{s} L_{p}}$ & $\xi_{0}<0.3$ \\
\hline $\begin{array}{l}\text { Pullen et al. } \\
\text { (2007) }\end{array}$ & $R_{2 \%}=1.65 \tan \sqrt{H_{m 0} L_{0}}$ & $\begin{array}{l}\text { Dikes (of outer } \\
\text { slope } \alpha \text { ) }\end{array}$ \\
\hline $\begin{array}{l}\text { Roberts et al. } \\
\text { (2010) }\end{array}$ & $R_{2 \%}=1.00 H_{b}$ & $\xi_{0}>0.3$ \\
\hline $\begin{array}{l}\text { Vousdoukas et al. } \\
\text { (2012) }\end{array}$ & $R_{2 \%}=0.53 \beta \sqrt{H_{s} L_{p}}+0.58 \tan \beta H_{s}+0.45$ & Reflective beaches \\
\hline $\begin{array}{l}\text { Poate et al. } \\
\text { (2016) }\end{array}$ & $R_{2 \%}=0.21 D_{50}^{-0.15} \sqrt{\tan \beta} H_{s} T_{m-1 m 0} H_{s}$ & $\begin{array}{l}\text { Gravel beaches } \\
0.05<\tan \beta<0.20\end{array}$ \\
\hline & simplified to: & \\
\hline & $R_{2 \%}=0.49 \sqrt{\tan \beta} T_{0} H_{s}$ & \\
\hline $\begin{array}{l}\text { Atkinson et al. } \\
\text { (2017) }\end{array}$ & $R_{2 \%}=0.92 \tan \beta \sqrt{H_{s} L_{p}}+0.16 H_{s}$ & Model of models \\
\hline
\end{tabular}

Table 2. Wave runup empirical formulations (non-exhaustive list). $\beta$ is the foreshore beach slope. $\Omega$ is the Dean parameter (Dean 1977), SWL is the still water level (see Nielsen and Hanslow, 1991). $\xi$ is calculated with respect to the deep water significant wave height $\left(\mathrm{H}_{\mathrm{s}}\right)$ and significant period $\left(\mathrm{T}_{\mathrm{s}}\right)$. $\xi_{\mathrm{p}}$ corresponds to the Iribarren number calculated using the peak period and significant wave height. $H_{s t}$ is the significant wave height and $H_{m 0}$ is the wave height at the toe of the slope (for structures such as dikes), $\mathrm{L}_{\mathrm{p}}$ is the peak period deep-water wave 
length, $L_{0}$ the deep-water wave length $L_{0, s}$ the deep-water wave length computed using the significant period. $H_{0}$ is the deep-water wave height. $\mathrm{D}_{\mathrm{s} 0}$ is the median sediment size.

\subsubsection{Hybrid models}

In comparison with the statistical downscaling models presented in section 3.2, the hybrid models are more focused on a local scale as they propagate hydrodynamic conditions. They combine statistical techniques and numerical models. They have been used to predict nearshore wave conditions, wave run-up or water level at the coast, based on offshore hydrodynamic conditions (see e.g. Camus et al. 2011; Gouldby et al. 2014; Rohmer and Idier, 2012; Gainza et al. 2018; Passarela et al. 2018). These hybrid models rely on the interpolation of processbased simulations or observations. In the former case, the first step is to define the process-based simulations to run (using for instance maximum dissimilarity algorithm as in Gainza et al. (2018); or adaptive sampling as in

605 Rohmer and Idier, (2012). For the interpolation, it can be done for instance by using radial basis functions (e.g. Camus et al. 2011; Gouldby et al. 2014), kriging (Rohmer and Idier, 2012), or genetic programming (Passarela et al. 2018). It should be noted that the quality of meta-models based on process-based simulations cannot be better than the used numerical model, and thus introduce additional errors. Passarella et al. (2018) used a genetic programming approach to predict the total and infragravity swash excursion from observed data sets extensively used in swash prediction studies. One of the originalities of this work is that the final solutions are selected based on a minimization of the error while ensuring the formula could be interpreted physically, and avoiding overfitting. While their approach reduce the prediction errors compared to well-established parameterization, as the one of Stockdon et al. (2006), it still depends on the learning dataset and the choice of the variables taken into account. The comparison (visual inspection) of the run-up prediction of that study (Figure 5 in Passarella et

615 al. 2018) and the modeling results of Nicolae-Lerma et al. (2016, Figure 4a therein) on the Truc Vert dataset show similar prediction quality. However, as highlighted by Passarella et al. (2018), even if the parameters they took into account $\left(\mathrm{H}_{0}, \mathrm{~T}_{\mathrm{p}}, \mathrm{L}_{0}, ß\right)$ are easily accessible they oversimplify the processes that affect swash. In addition, it is unknown how the predictors will perform in settings beyond those of their work, contrary to the kriging method which provides an error estimate.

620

4.3 Wave contribution to coastal sea level changes

In Section 2, we have shown how wave-induced processes could impact the sea level at the coast. These local processes are mostly controlled by offshore wave conditions, particularly the significant wave height and the wave period, which have been shown (Section 3) to vary significantly over decadal time scales, due to internal

625 climate oscillations. Given the projected changes in atmospheric circulation induced by external forcing, it is likely that the wave climate will respond to these changes and adapt to the future wind regimes. The ensemble modelling of projected change in wave conditions realised during the COWCLIP project provides a global picture of the potential wave conditions for the end of the 21st century (see Figure 7 and Section 3.4). Such changes will likely impact future coastal sea level. In addition, other interactions between waves and sea level need to be taken into account in order to understand the contribution of waves to coastal sea level. For instance, changes in water-depth due to sea level rise will relax the depth-limitation of waves, and could lead to higher, and longer-period waves reaching the coast. These aspects are presented in this section. 
Global scale studies of coastal sea level changes or flood related risk assessments are often based on tide gauge

records, which are mostly located in wave-sheltered areas. Yet, regional to global scale studies accounting for wave contributions to past (e.g. Vousdoukas et al. 2016, Serafin et al. 2017, Rueda et al. 2017, Melet et al. 2018) and projected extreme sea levels (ESL) at the coast are emerging (e.g. Vousdoukas et al. 2017, 2018a, b, Vitousek et al. 2017, Arns et al. 2017), although often assuming stationarity in the wave climate from past to future climate. These studies pinpoint the sizeable effects of wave contributions and the need to include them for

Vitousek et al. (2017) reported that when accounting for wave setup, wave runup, tides and storm surges, a sea level rise of only 5-10 cm (expected to occur between 2030 and 2050) doubles the flooding frequency in many regions, particularly in the Tropics. Arns et al. (2017) reported that when accounting for wave contributions in

645 future ESL, coastal protection design heights need to be increased by roughly 50\% in the German Bight region relative to design heights inferred solely on sea level rise. Focusing on future ESL along European coasts, Vousdoukas et al. (2017) showed that projected changes in storm surges and waves can substantially either enhance the effects of relative sea level rise (along the majority of northern European coasts, locally with contributions up to 40\%), or reduce it (along the Portuguese coast and the Gulf of Cadiz where reductions in surge and wave extremes offset relative sea level rise by 20-30\%). Global projections of ESL at the coast were recently provided by Vousdoukas et al. (2018a), accounting for wave setup. They reported a very likely increase of the globally averaged 100-year ESL of 34-76 cm under a moderate-emission-mitigation-policy scenario and of 58-172 cm under a business as usual scenario with wave setup being a non-dominant contributor to changes in extreme events. The important influence of changing wave contributions to coastal flooding due to increased water depth with sea level rise was also reported in other studies (e.g. Hoeke et al. 2015, Wandres et al. 2017).

Wave setup and runup amplitude are modulated at longer timescales, notably through their dependence on offshore wave conditions. Wave height, period and direction vary over a broad range of timescales, from seasonal to interannual and multidecadal scales in response to both internal climate variability (e.g. seasonality in storminess, climate modes of variability such as ENSO) and to climate change (section 3, see also

660 Woodworth et al. 2019). Long-term changes in offshore wave conditions can therefore modulate wave energy fluxes and extreme water levels at the coast (e.g. Barnard et al. 2015, Mentaschi et al. 2017), and affect wave setup and swash at long time-scales. Melet et al. (2016) reported a large contribution from wave runup to past changes in total coastal water level in the Gulf of Guinea at seasonal time-scales. A first-order, quasi-global estimate of wave setup and swash contribution to interannual-to-decadal coastal water-level changes was recently provided by Melet et al. (2018), considering wave setup and runup changes induced only by changes in offshore wave height and period. Interannual-to-decadal wave setup changes were found to be significant in over large parts of the world coastline over the last two decades compared to other contributors to coastal sea level changes (see Melet et al. 2018, and Figure 10 herein). As reported by Serafin et al. (2017), who investigated the relative contribution of tides, waves, and nontidal residuals to extreme total water levels at the

670 shoreline of US West Coast sandy beaches, regional differences in the magnitude of extreme total water levels can be attributed, in part, to changes in incident wave conditions through their contribution to the wave setup 
and wave runup. Therefore, the offshore regional wave climate variability presented in Section 3 may explain the regional differences in coastal sea level changes reported by several authors (e.g. Melet et al. 2018; Vousdoukas et al. 2018). For some regions, changes in the wave setup can substantially either enhance or attenuate the effect of thermal expansion and ice mass transfer from land over periods of several decades. Melet et al. (2018) found that changes in the wave runup over the past two decades were mostly caused by internal climate variability.

It is important to stress that most of the aforementioned studies on the contribution of waves-induced processes to ESL and sea level changes at global scale use empirical parameterizations with approximated inputs, which can hardly provide accurate estimates and sharp conclusions on the potential role of waves on global coastal water levels (see the comments from Aucan et al. 2019, and the associated response from Melet et al.: Aucan et al. 2019; Melet et al. 2019). The most important limitations of these approaches are therefore discussed in a dedicated Section (5.4). However, all these studies converge to show that given the actual projections of future wave climate, it is likely that wave-induced processes will significantly impact future trends in coastal sea level, which need to be taken into account in future studies on regional sea level change projections.

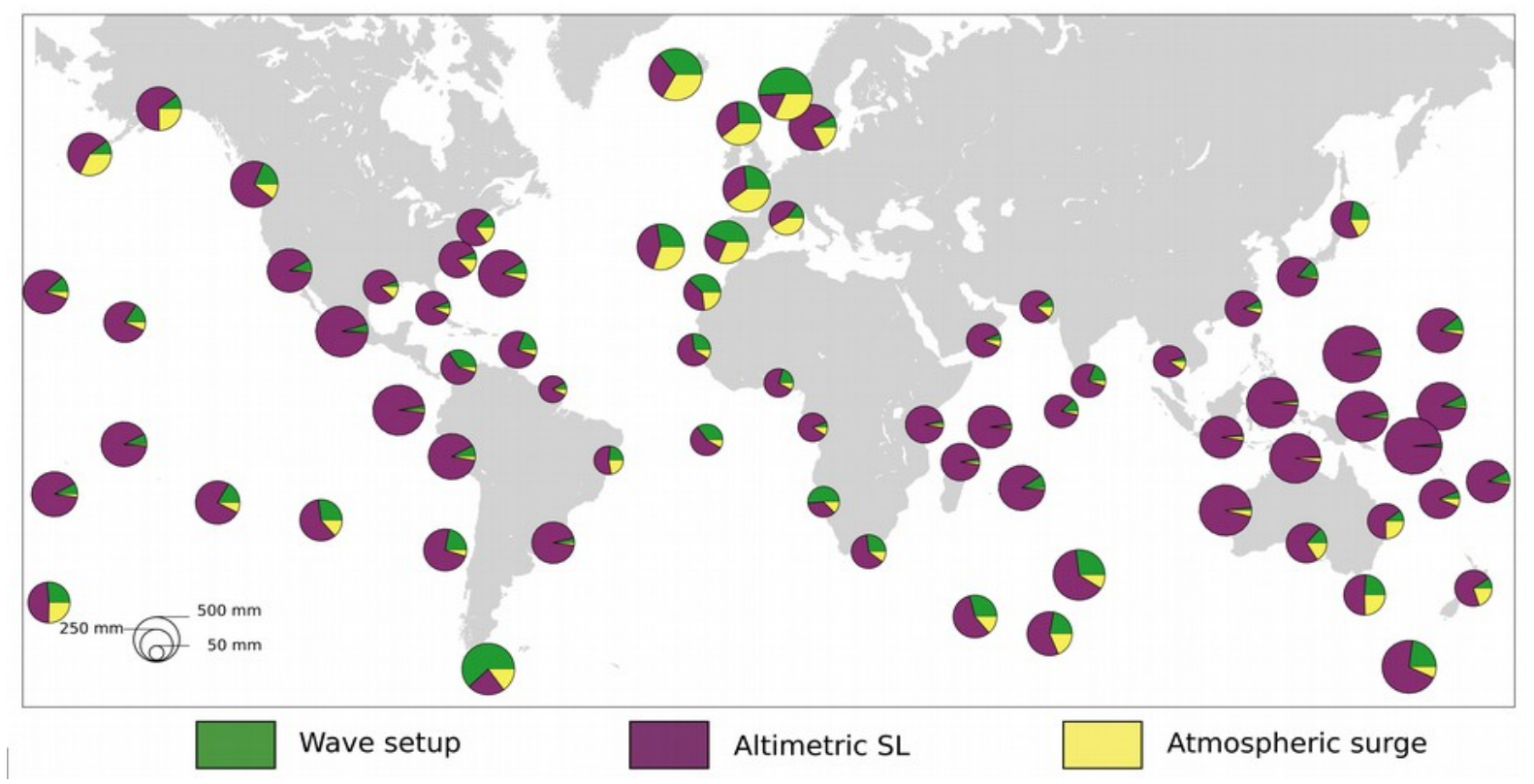

Fig.10 Pie charts of the relative contribution of wave setup (green), altimetry-derived sea level (violet) and atmospheric surges (yellow) to total water-level detrended interannual-to-multidecadal variations over 19932015. The size of the pie charts indicates the standard deviation of detrended interannual-to-multidecadal sealevel variations, with scalings on the lower left corner. Wave setup was estimated from the Stockdon et al. (2006) generic formulation with a spatially uniform shoreface slope of 0.05 and ERA-interim deep-water wave height and period. Adapted from Melet et al. 2018

\subsection{Interactions with other MSL related processes}

Several interactions between waves and lower frequency sea-level components can be identified, amongst which: (1) the effect of water depth modulation and currents on waves, (2) the effect of waves on atmospheric storm surge. Here, we introduce studies providing quantifications of these effects, mainly based on Idier et al. 
(submitted), who also detail the related mechanisms.

In the nearshore, tides can significantly modify short waves. First, tide-induced water level variations shifts the cross-shore position of the surfzone, so that wave heights are modulated along a tidal cycle (e.g. Dodet et al. 2013). In addition, strong tidal currents (as in straits, estuaries or tidal inlets) can affect the waves (Rusu et al. 2011). As a consequence, wave setup along the shoreline or inside estuary can exhibit tidal modulations with a 705 wave setup being smaller at high tide than at low tide (see e.g. Kim et al. 2008), or the opposite (Dodet et al. 2018), depending on the curvature of the foreshore slope. At a given location, modulations of several centimeters to tens centimeters have been estimated in many studies, both in estuaries (see e.g. Fortunato et al. 2017 ; Tagus estuary, Portugal) or on wave dominated beaches (see e.g. Pedreros et al. 2018; Truc Vert Beach, France). As an additional mechanism, we should note that in estuaries, the wave setup can be also amplified

710 through a resonant process (Fortunato et al. 2017).

Several studies investigated the effect of SLR on waves, taking into account tide changes or tide and atmospheric storm surges changes (see e.g. Chini et al. 2010; Arns et al. 2017). In the German Bight, at the exposed westward oriented coast, the modeling results of Arns et al. (2017) show that the significant wave

715 height of the most damaging combination (still water level, wave height) of probability 0.01/year would exceed the present conditions by up to $0.25 \mathrm{~m}(0.78 \mathrm{~m})$, for SLR=0.54 $\mathrm{m}(1.74 \mathrm{~m})$. They also show that with the sealevel rise, at a given location, the tide-induced modulation of waves decrease (see e.g. Arns et al. 2017). However, the absolute results of these studies should be used with caution as the bathymetry is generally assumed unchanged (which is a strong assumption considering that sea-level rise should have significant effect).

720

Waves and wave setup are modified by water depth and currents, but they also have an effect on atmospheric storm surges, as the surface stress also depends on the sea state, through the sea surface roughness (see e.g. Stewart, 2014). These modifications of sea-surface roughness by waves can lead to atmospheric surge amplification up to tens of centimeters. For instance, in the Bay of Biscay, Bertin et al. (2012) compared, for the Xynthia (2010) event, the atmospheric surges obtained with quadratic formulation to the ones obtained with wave-dependent parameterization to compute wind stress. Both approaches perform similarly except during the storm peak, where the surge with the wave-dependent parameterization is several tens of centimeters larger. Similar order of magnitudes are obtained for instance in the North Sea (Mastenbroek et al. 1993) or the Taiwan Strait (Zhang et al. 2010).

In coastal zones, the near-bottom orbital velocities associated with the propagation of short waves can become large and enhance bottom stress (Grant and Madsen, 1986), including the formation of ripples (Ardhuin et al. 2002). This enhancement should reduce the storm surges. However, this effect remains to be validated with field measurements in shallow-water.

\section{Limitation and Perspectives}

5.1 Waves measurements

With seven altimeters in operations as of September 2018 (Figure 4a), offshore wave heights are better 
monitored than ever, and higher along-track resolution is now available thanks to improved retracking and filtering. Because wave-induced sea level at the coast is a function of the wave periods (e.g. Stockdon et al. 2006, Poate et al. 2016, Dodet et al. 2018) and directional wave properties (Guza and Feddersen 2012), the availability of spectral wave information is critical. For large ocean basins, and in particular in the Pacific, SARderived swell measurements, such as from Sentinel-1, is a very rich source of data. Extending such measurements to shorter wave periods will allow the monitoring of wave periods and directions in and near storms, and in smaller basins. Indeed the main limitation of SARs is due to the blurring associated with orbital velocities (Alpers and Rufenach, 1979), which limits the effective resolution of waves that propagate in the satellite flight direction. This blurring is proportional to the altitude of the satellite. As a result, conditions are generally not satisfactory for measuring waves with SARs in enclosed basins or off eastern coasts (Figure 11a). This is the main motivation for the development of specific "wave spectrometers", based on a conically scanning Real Aperture Radars (RARs, see Jackson et al. 1985; Hauser et al. 2017; Nouguier et al. 2018). The first satellite to carry such a Ku-band RAR instrument is CFOSAT, successfully launched on 29 October 2018. This instrument is expected to resolve waves as short as $70 \mathrm{~m}$, with a $180^{\circ}$ ambiguity on the wave propagation direction (Figure 11b). The next generation of such instrument is SKIM, resolving much shorter wavelengths without direction ambiguity thanks to a Doppler measurement, and could be launched in 2025 (Ardhuin et al. 2018). Such a resolution would allow the measurement of dominant waves in all seas, with a typical revisit time of 4 days (Figure 11c).

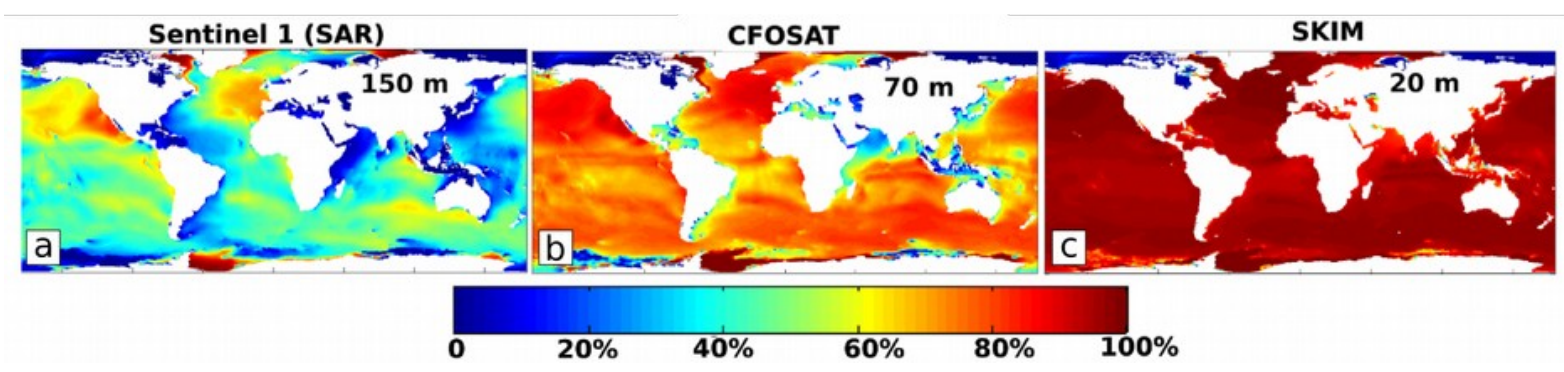

Fig.11 Average fraction of simulated wave energy in January 2014 resolved when using a cut-off wavelength of

$150 \mathrm{~m}$ (A), $70 \mathrm{~m}$ (B) and $20 \mathrm{~m}$ (C). Note that low values in the Arctic and other ice-covered regions are an artefact of the model that does not properly represent wave-ice interactions. January 2014 was very stormy in the North Atlantic.

All these wave measurements fail very close to the shore (50 km for altimeters, a few meters for SARs with a strong perturbation by the surf zone), and are typically used for validating the offshore part of numerical wave models that simulate waves up to the coast. However, Recent developments in processing (e.g. Passaro et al. 2015; Ardhuin et al. 2017) or filtering techniques (Quilfen et al. 2018) are now allowing to use data at much higher resolution, possibly down to $20 \mathrm{~km}$, whereas standard wave heights from altimeters (e.g. Sepulveda et al. 2015) are typically dominated by noise for scales shorter than $50 \mathrm{~km}$.

For what concerns our understanding of the complex wave deformation in the surf zone, new insights have been obtained with LiDAR scanners deployed along a pier at Saltburn beach, UK (Martins et al. 2017). This technique provides measurements of the sea surface elevation from the break point to the runup limit at spatial 
(centimeters) and temporal $(25 \mathrm{~Hz})$ resolutions rarely achieved in field conditions. Such innovative measurements will undoubtedly foster our understanding of depth-limited wave breaking mechanism and swash zone hydrodynamics, and improve the accuracy of parametric formula used to infer nearshore parameters from deep-water wave measurements.

The modelling of waves right up to the coast requires a good knowledge of nearshore depths and currents that is missing in many regions. With some progress coming from the exceptional coverage of new optical sensors mounted on board of satellites such as Sentinel 2, both radiance-based methods (e.g. Purkis 2018) and new methods based on dispersion (e.g. Kudryavtsev et al. 2017, Romeiser and Graber 2018) will certainly lead to rapid progress on this topic. In addition, altimeter data can be efficiently used to apply directional correction to modeled wind sea and swell wave height, as demonstrated by Albuquerque et al. (2018).

785

Finally, the satellite remote sensing of a sea level that include wave effects, right at the coast, has not yet been demonstrated. Today's nadir altimeters only provide offshore sea levels, and it is unclear how much the noise in future measurements of SWOT’s across-track SAR interferometer (Durand et al. 2010) may corrupt data across the surf zone, with additional velocity bunching and azimuthal cut-off effects.

790

\subsection{Coastal bathymetry}

Recent studies have shown that extreme winter wave conditions can have a dramatic impact on beach morphologies at regional scale and over pluri-annual time periods (Masselink et al. 2016; Dodet et al. 2019). Therefore, it seems over-simplistic to consider that coastal vulnerability (shoreline retreat and flooding) can be represented as a simple response to sea level change, assuming passive coastal bathymetry. Although constant efforts by the research community have been made toward either simple or complex paradigms of coastal evolution (e.g, static retreat by Bruun, 1962; Hanson et al. 2010), the coastal response to perpetually changing ocean forcing conditions is still unclear (Cooper and Pilkey, 2004; Ranasinghe et al. 2016). Recently, several methods using satellite imagery have been proven reliable (Poupardin et al. 2016; Bergsma et al. 2019; Almar et al. 2019; Raucoules et al. 2019) in estimating large-sale coastal bathymetry at unprecedented resolution. One prominent approach is the use of multispectral imagery in estimating shallow bathymetry, until $20 \mathrm{~m}$ depth approximately in the case of clear waters. However, many coastal waters are very turbid and this method requires ground-based calibration, which limits this technique to accessible areas. Other techniques to estimate bathymetry from optical or radar imagery make use of the wavelengths change during the shoaling of ocean waves. This allows resolving depths up to 40-50 $\mathrm{m}$ in regions where long swells are present. Among these methods, some use external data (measurements or offshore modeling), while others directly extract the wavelength and wave celerity informations from the satellite images. Despite their high potential, these methods were only applied to a limited spatial domain (Danilo and Melgani, 2016; Poupardin et al. 2016) using basic wave physics (none uses the information contained in the full spectrum in an optimal way), and can still be improved. Having access to high-resolution coastal bathymetry is one major prerequisite in order to reduce uncertainty in the estimation of wave contribution to coastal sea level changes (e.g. Melet et al. 2018), and the aforementioned studies appear as promising avenue to tackle this challenge. 
5.3 Stochastic character of wind generated waves

815 Our ability to predict wave overtopping is crucial for coastal management. It should be reminded that an infinite number of time series could occur for a same wave spectrum (Tuah and Hudspeth, 1982). Pearson et al. (2001) raised the issue of the relationship between the length of the time series and the accuracy of the overtopping estimate. Pullen et al. (2007) recommends to simulate a sequence of 1000 waves for each sea state tested. Pearson et al. (2001) and Romano et al. (2015) noticed that the overtopping discharge from tests using series of

820500 waves, is very close to that from tests with 1000 waves, while Williams et al. (2014) show that using more than 1000 waves does not affect the overtopping estimate. This suggests that the effect of stochastic character of waves on overtopping discharge depends on the time span during which the parameters influencing the waves are almost constant. Considering a wave period of $12 \mathrm{~s}$, the time span should be larger than $1 \mathrm{~h} 40 \mathrm{~min}$. In microtidal environment, such conditions could be met. However, in macro-tidal environments, as highlighted in

825 section 4.4, nearshore waves are modulated by tides, and water level can exhibit changes up to a few meters in a single hour. This implies that the stochastic character of waves should have a significant effect on flood occurrence or overtopping discharge, especially in macro-tidal environment. This subject should deserve more attention in the future.

\subsection{Empirical formulations for wave setup and runup}

While wave setup and runup derived from empirical formulations can compare well to observations when local characteristics of the coast are available (e.g. Vousdoukas et al. 2009, Stockdon et al. 2006), this approach can lead to uncertain results at global scales for several reasons: first, generic formulations of wave setup and runup involve the foreshore slope, which vary significantly in space and time (e.g. Hoeke et al. 2015; Karunarathna et

835 al. 2016; Diez et al. 2017), and are usually within the 1\%-20\% range (e.g. Komar, 1998; Defeo and McLachlan, 2013). Yet, as foreshore beach slopes are unknown over most of the world coastlines, regional to global scale studies have used constant values of the foreshore beach slope (e.g. Melet et al. 2018, Serafin et al. 2017), constant values of sediment-grain-size to infer beach slopes (Rueda et al. 2017), or formulations specific to dissipative beaches that do not depend on the beach slope (e.g. Vitousek et al. 2017). Wave setup estimates are

840 very sensitive to the beach slope value and to the chosen empirical formulation, so that reported wave setup contributions are therefore to be modulated by the local beach slope compared to estimates using a uniform spatial value. It should also be noted that accounting for the variability of the beach slope should modulate the spatial heterogeneity of wave setup changes. Second, the widely used empirical formulation of Stockdon et al. (2006) for wave setup and runup has been derived from field observations on sandy beaches, and do not encompass the variety of coastal environments that can be found worldwide (gravel beaches, cliffs, armoured coasts, etc). It is therefore important to test and derive new empirical formula for other types of environment. In addition, deep-water wave characteristics derived from global numerical models to estimate wave setup and runup from empirical formulations also come with limitations. In particular for extreme events, storm winds tend to be underestimated in global simulations (especially for tropical cyclones). Finally, global scale studies of coastal sea level changes including the contribution from wave setup or runup do not account for interactions between the different contributors to sea level changes (e.g. tides, waves, surges, ocean circulation, SLR) as global scale numerical modelling studies including all the aforementioned processes are not available yet. 


\subsection{Projections from General Circulation Models}

855 Predicting how wave-induced processes will contribute to future coastal sea level changes requires accurate information on future wave conditions. For this purpose, General Circulation Models integrate the major physical processes of the atmosphere, ocean, cryosphere and land surface in order to simulate the response of the global climate system to increasing greenhouse gas concentrations. Although GCMs are extremely valuable tools to estimate the magnitude and trends of essential climate variables in the near future, their results are

860 flawed by cumulative uncertainties inherent to each layer that constitutes these complex modelling systems (e.g. expected accumulation of greenhouse gases and aerosols in the atmosphere, response of the atmospheric circulation, interactions with the hydrosphere, cryosphere, lithosphere and biosphere, global-to-regional downscaling). For what concerns ocean waves, the main driver is the atmospheric circulation, and more particularly the $10-\mathrm{m}$ wind fields that are usually used to force numerical wave models. As stated in the $5^{\text {th }}$

865 Annual Report of the IPCC (chapter 13, Church et al. 2013), there is low confidence in global wave model projections because of uncertainties regarding future wind states, particularly storm geography, the limited number of model simulations used in the ensemble averages, and the different methodologies used to downscale climate model results to regional scales (Hemer et al. 2013b). In a recent paper, Morim et al. (2019) analyses 91 published global and regional wave climate projection studies and found a lack of consensus for projections of

870 Hs over the eastern north Pacific and southern Indian and Atlantic Oceans, and everywhere, except for the Southern Ocean and the North Atlantic, for extreme Hs. They also note a distinct lack of research regarding projected changes in wave direction, which is of critical importance for the impact of waves on coastal sea level. Finally, they recommend a shift towards a systematic, community-based framework (as proposed by the Coordinated Ocean Wave Climate Project - COWCLIP, Hemet et al., 2018) to foster concerted efforts and to

875 better inform the wide range of relevant decisions across ocean and coastal adaptation and mitigation assessments.

\section{Conclusion}

We have seen that the coastal sea level, as observed at the shores of exposed coastlines, is strongly influenced

880 by wave-induced processes. Despite its central importance for risk mitigation and sustainable management of the coastal zone, the coastal sea level has for long been assimilated to the sea level estimated from tidal gauges located in sheltered areas, where the effect of the waves is hardly visible. In addition, the rich information on global sea level variability recorded by satellite altimeters over the last 30 years cannot be extrapolated to the coast where the presence of lands degrades altimeter echoes. As a consequence, our understanding of the regional and long-term variability of coastal sea level, and particularly its wave-related components, is still very limited. We claim in this paper that this topic deserves much attention. The three major wave-related processes that affect coastal sea level are 1) the wave setup: a tilt of the water surface in the surf zone caused by the rapid dissipation of wave energy at the breaking point; 2) the wave runup: the vertical excursion of the waterline when the waves enter the swash zone; 3$)$ the infragravity waves: low-frequency $(\sim 0.01 \mathrm{~Hz})$ oscillations of the water surface bound to and travelling with the wave groups that increase in size in the shoaling and breaking zone and significantly contribute to the swash motions. All these processes are controlled by offshore wave parameters, such as the significant wave height, the wave period and the wave direction. Given the strong variabilities (seasonal, inter-annual, decadal) of incident offshore wave conditions, the contribution of wave-related 
components is known to impact coastal sea level over a wide range of scales. Moreover, a number of studies on past and and future trends in wave conditions indicate that significant changes in the height, direction and periods of wind generated waves are imprinted by internal and external climate variabilities. These long-term changes in wave conditions will likely affect coastal sea level, and preliminary assessments of the wave-related contribution to coastal sea level have already confirmed this idea. However, severe limitations still restrain a clear understanding about the role of waves on coastal sea level variability. These limitations concerns: the lack of satellite information at the coast and on the wave period and direction, the difficulty to obtain accurate bathymetric information in the nearshore, where bottom features are constantly evolving, the high computational cost of high resolution model needed to resolve the complex wave transformation from deep water to the shore, the overly simplistic form of empirical models used to derive wave setup and runup from offshore wave parameters, and the large uncertainties associated with future projections of wind and wave conditions at regional scales. Fortunately, great advances are currently shaping the fields of remote sensing observations, geophysical data analysis, and high level computer science, which will pave the way for a deeper understanding of the contribution of wind generated waves to coastal sea level.

\section{Acknowledgments}

910 This paper arose from the international workshop on "Understanding the Relationship between Coastal Sea Level and Large Scale Ocean Circulation” held at the International Space Science Institute (ISSI), Bern, Switzerland on 59 March 2018. The authors are grateful to Anny Cazenave for taking in charge the implementation of this Special Issue. GD is supported by the ESA Sea State Climate Change Initiative. FA is supported by Labex Mer via grant ANR-10-LABX-19-01, and the ESA Sea State Climate Change Initiative. XB

915 is supported by the Regional Chair Project EVEX DI is supported by BRGM and ANR projects (PSO COTIER and RISCOPE) and is thankful to Jérémy Rohmer for constructive discussions on the meta-models.

\section{References}

Abessolo Ondoa G, Almar R, Castelle B, Testut L, Leger F, Bonou F, Bergsma E, Meyssignac B, and Larson M

920 (2019) On the use of shore-based video camera to monitor sea level at the coast: A case study in grand popo, benin (gulf of guinea, west africa). Journal of Atmospheric and Oceanic Technology, In review

Albuquerque J, Antolínez JAA, Rueda A, Méndez FJ, Coco G (2018) Directional correction of modeled sea and swell wave heights using satellite altimeter data. Ocean Modelling 131, 103-114. https://doi.org/10.1016/j.ocemod.2018.09.001

925 Allender J, Audunson T, Barstow SF, Bjerken S, Krogstad HE, Steinbakke P, Vardtal L, Borgman LE, Graham C (1989) The WADIC project: a comprehensive field evaluation of directional wave instrumentation. Ocean Eng. 16:505-536

Almar R, Blenkinsopp C, Almeida LP, Cienfuegos R, Catalan P (2017) Wave runup video motion detection using the Radon Transform, Coastal Engineering, 130, 46-51

930 Almar R, Bergsma EWJ, Maisongrande P, Melo de Almeida LP (2019) Coastal bathymetry from optical 
submetric satellite video sequence: a showcase with Pleiades persistent mode. Remote Sensing of Environment. In review

Almeida LP, Masselink, G, Russell, PE, Davidson, MA (2015) Observations of gravel beach dynamics during high energy wave conditions using a laser scanner. Geomorphology 228, 15-27. https://doi.org/10.1016/j.geomorph.2014.08.019

Almeida LP, Almar R, Meyssignac B, and Viet NT (2018) Contributions to coastal flooding events in southeast of Vietnam and their link with global mean sea level rise. Geosciences, 8:437

Alpers W, Rufenach C (1979) The effect of orbital motions on synthetic aperture radar imagery of ocean waves. IEEE Transactions on Antennas and Propagation 27, 685-690. https://doi.org/10.1109/TAP1979.1142163

940 Aouf L, Lefèvre JM, Hauser D, Chapron B (2006) On the combined assimilation of RA-2 altimeter and ASAR wave data for the improvement of wave forecasting, in Proceedings of 15 Years of Radar Altimetry Symposium, Venice, March 13-18, 2006

Apotsos A, Raubenheimer B, Elgar S, Guza R, Smith JA (2007) Effects of wave rollers and bottom stress on wave setup. Journal of Geophysical Research Oceans 112 C2 C02003

Ardhuin F, Drake TG, Herbers THC (2002) Observations of wave-generated vortex ripples on the North Carolina continental shelf. Journal of Geophysical Research: Oceans 107, 7-1-7-14. https://doi.org/10.1029/2001JC000986

950

Ardhuin F, Rascle N, Belibassakis KA (2008a) Explicit wave-averaged primitive equations using a generalized lagrangian mean. Ocean Modelling 20 (1):35-60

Ardhuin F, Jenkins AD, Belibassakis KA (2008b) Comments on the three-dimensional current and surface wave 955 equations. Journal of Physical Oceanography 38 (6): 1340-1350

Ardhuin F, Drake TG, Herbers THC (2002) Observations of wave-generated vortex ripples on the North Carolina continental shelf. J Geophys. Res. 107 C10. doi:10.1029/2001JC000986

Ardhuin F, Herbers THC, Jessen PF, O’Reilly WC (2003) Swell transformation across the continental shelf. part II: validation of a spectral energy balance equation. J Phys. Oceanogr. 33:1940-1953

Ardhuin F, Rascle N, Belibassakis KA (2008) Explicit wave-averaged primitive equations using a generalized Lagrangian mean. Ocean Modelling 20, 35-60. https://doi.org/10.1016/j.ocemod.2007.07.001

Ardhuin F, Rascle N, Chapron B, Gula J, Molemaker J, Gille ST, Menemenlis D, Rocha C (2017) Small scale currents have large effects on wind wave heights. J Geophys. Res. 122 C6:4500-4517. 
doi:10.1002/2016JC012413

970 Ardhuin F, Orfila A (2018) Wind waves, in: New Frontiers in Operational Oceanography, ch. 14, $393-422$. doi:10.17125/gov2018.ch14

Ardhuin F, Aksenov Y, Benetazzo A, Bertino L, Brandt P, Caubet E, Chapron B, Collard F, Cravatte S et al. (2018) Measuring currents, ice drift, and waves from space: the Sea surface KInematics Multiscale monitoring (SKIM) concept. Ocean Sci. 14:337-354. doi:10.5194/os-2017-65

Arns A, Wahl T, Dangendorf S, Jensen J, Pattiaratchi C (2017) Sea-level rise induced amplification of coastal protection design heights. Nature Sci Rep. https://doi.org/10.1038/srep40171

980 Atkinson AL, Power HE, Moura T, Hammond T, Callaghan DP and Baldock TE (2017) Assessment of runup predictions by empirical models on non-truncated beaches on the south-east Australian coast. Coastal Engineering, 119, 15-31

Aucan J, Hoeke RK, Storlazzi CD, Stopa J, Wandres M, Lowe R (2019) Waves do not contribute to global sea985 level rise. Nat Clim Change 9:2. https://doi.org/10.1038/s41558-018-0377-5

Barber NF, Ursell F, Darbyshire J, Tucker MJ (1946) A frequency analyser used in the study of ocean waves. Nature 329-335

990 Barnard PL, Short AD, Harley MD, Splinter KD, Vitousek S, Turner IL, Allan J, Banno,M, Bryan KR, Doria A, Hansen JE, Kato S, Kuriyama Y, Randall-Goodwin E, Ruggiero P, Walker IJ, Heathfield DK (2015) Coastal vulnerability across the Pacific dominated by El Niño/Southern Oscillation. Nature Geoscience 8, 801-807. https://doi.org/10.1038/ngeo2539

Battjes JA (1974) Surf Similarity. Proceedings of the 14th Conference of Coastal Engineering. ASCE, 466-48

Battjes JA, Bakkenes HJ, Janssen TT, van Dongeren AR (2004) Shoaling of subharmonic gravity waves. Journal of Geophysical Research 109 c02009. doi:10.1029/2003JC001863

1000 Bennis AC, Dumas F, Ardhuin F, Blanke B (2014) Mixing parameterization: Impacts on rip currents and wave set-up. Ocean Engineering 84:213-227

Bertin X, Bruneau N, Breilh JF, Fortunato AB, Karpytchev M (2012) Importance of wave age and resonance in storm surges: The case Xynthia, Bay of Biscay. Ocean Model 42:16-30, https://doi.org/10.1016/j.ocemod.2011.11.001

Bertin X, Prouteau E, Letetrel C (2013) A significant increase in wave height in the North Atlantic Ocean over 
the 20th century. Global and Planetary Change. https://doi.org/10.1016/j.gloplacha.2013.03.009

1010 Bertin X, Li K, Roland A, Bidlot JR (2015) The contribution of short-waves in storm surges: two case studies in the Bay of Biscay. Continental Shelf Research 96:1-15

Bertin X, Olabarrieta M, MacCall R (2017) Hydrodynamics under storm conditions, in: Coastal Storms: Processes and Impacts. John Wiley and Son

1015

Bertin X, de Bakker A, van Dongeren A, Coco G, André G, Ardhuin F, Bonneton P, Bouchette F, Castelle B, Crawford WC, Davidson M, Deen M, Dodet G, Guérin T, Inch K, Leckler F, McCall R, Muller H, Olabarrieta M, Roelvink D, Ruessink G, Sous D, Stutzmann E, Tissier M (2018). Infragravity waves: From driving mechanisms to impacts. Earth-Science Reviews 177, 774-799. https://doi.org/10.1016/j.earscirev.2018.01.002

Bergsma EWJ and Almar R, (2018). Video-based depth inversion techniques, A method comparison with synthetic cases. Coastal Engineering 138, 199-209

Bergsma EWJ, Almar R and Maisongrande P (2019) Radon-augmented SentinelII satellite imagery to derive 1025 wave-patterns and regional bathymetry, IEEE Transaction on Geosciences and Remote Sensing. In review

Bidlot JR (2017) Intercomparison of operational wave forecasting systems against buoys: data from ECMWF, MetOffice, FNMOC, ECCC, NCEP, MeteoFrance, DWD, BoM, SHOM, JMA, KMA, Puerto del Estado, DMI, NZM, METNO, SHN-SM, September 2017 to November 2017, tech. rep, Joint WMO-IOC Technical Commission for Oceanography and Marine Meteorology, 2017

Biesel F (1952) Équations générales au second ordre de la houle irrégulière. La Houille Blanche 7 (3):372-376. doi:10.1051/lhb/1952033

Bonneton P, Barthelemy E, Chazel F, Cienfuegos R, Lannes D, Marche F, Tissier M (2011) Recent advances in 1035 Serre-Green Naghdi modelling for wave transformation, breaking and runup processes. European Journal of Mechanics B Fluids 30:589-597

Bonneton A, Lannes D, Martins K, Michallet H (2017) Nonlinear weakly dispersive method for recovering the elevation of irrotational surface waves from pressure measurements. Coastal Engineering,

1040 https://doi.org/10.1016/j.coastaleng.2018.04.005

Bowen AJ, Inman DL, Simmons VP (1968) Wave 'set-down' and set-Up. J Geophys. Res. 73:2569-2577. https://doi.org/10.1029/JB073i008p02569

1045 Bowen AJ (1969) Rip currents. Theoretical investigations. Journal of Geophysical Research 74:5467-5478 
Bowen AJ, Guza R (1978) Edge waves and surf beat. Journal of Geophysical Research 83:1913-1920

Brodie KL, Raubenheimer B, Elgar S, Slocum RK, McNinch JE (2015) Lidar and Pressure Measurements of 1050 Inner-Surfzone Waves and Setup. J Atmos. Oceanic Technol. 32:1945-1959. https://doi.org/10.1175/JTECH-D$\underline{14-00222.1}$

Brodie KL, Palmsten ML, Hesser TJ, Dickhudt PJ, Raubenheimer B, Ladner H, and Elgar S (2018) Evaluation of video-based linear depth inversion performance and applications using altimeters and hydrographic surveys

1055 in a wide range of environmental conditions. Coastal Engineering, 136:147-160

Bromirski PD, Cayan DR, and Flick RE (2013) Wave spectral energy variability in the northeast Pacific, J Geophys. Res, 110, C03005, 2005. doi:10.1029/2004JC002398

1060 Bruneau N, Fortunato AB, Dodet G, Freire P, Oliveira A, Bertin X (2011) Future evolution of a tidal inlet due to changes in wave climate, Sea level and lagoon morphology (Óbidos lagoon, Portugal). Continental Shelf Research 31, 1915-1930. https://doi.org/10.1016/j.csr.2011.09.001

Camus P, Mendez FJ, Medina R (2011) A hybrid efficient method to downscale wave climate to coastal areas. 1065 Coastal Eng 58:851-862. https://doi.org/10.1016/j.coastaleng.2011.05.007

Camus P, Mendez FJ, Medina R, Tomas A, Izaguirre C (2013) High resolution downscaled ocean waves (DOW) reanalysis in coastal areas. Coast Eng 72:56-68. https://doi.org/10.1016/j.coastaleng.2012.09.002

1070 Camus P, Mendez FJ, Losada I Menendez M, Espejo A, Pérez J, Rueda A, Guanche Y (2014a) A method for finding the optimal predictor indices for local wave climate conditions. Ocean Dyn 64:1025-1038. https://doi.org/10.1007/s10236-014-0737-2

Camus P, Menendez M, Mendez FJ, Izaguirre C, Espejo A, Canovas V, Perez J, Rueda A, Losada,IJ and 1075 Medina R (2014b) A weather-type statistical downscaling framework for ocean wave climate,J Geophys. Res.Oceans,119, 7389-7405, doi:10.1002/2014JC010141

Camus P, Losada IJ, Izaguirre C, Espejo A, Menéndez M, Pérez J (2017) Statistical wave climate projections for coastal impact assessments. Earth’s Future 5:918-933. https://doi.org/10.1002/2017EF000609

Carrier GF, Greenspan,HP (1958) Water waves of finite amplitude on a sloping beach. Journal of Fluid Mechanics 4, 97-109. https://doi.org/10.1017/S0022112058000331

Casas-Prat M, Wang XL, Swart N (2018) CMIP5-based global wave climate projections including the entire 1085 Arctic Ocean. Ocean Modelling 123, 66-85. https://doi.org/10.1016/j.ocemod.2017.12.003 
Cazenave A, Cozannet GL (2014) Sea level rise and its coastal impacts. Earth’s Future 2, 15-34. https://doi.org/ 10.1002/2013EF000188

1090 Cazenave et. al (WCRP Global Sea Level Budget Group) (2018) Global sea-level budget 1993-present. Earth System Science Data 10, 1551-1590. https://doi.org/10.5194/essd-10-1551-2018

Charles E, Idier D, Thiébot J, Le Cozannet G, Pedreros R, Ardhuin A, Planton S (2012) Present Wave Climate in the Bay of Biscay: Spatiotemporal Variability and Trends from 1958 to 2001. J Climate, 25, 2020-2039, https://doi.org/10.1175/JCLI-D-11-00086.1

Chen Q, Kirby JT, Dalrymple RA, Shi F, and Thornton EB (2002) Boussinesq modeling of longshore currents. J Geophys. Res, 108, C11, p. 3362, 2003. doi:10.1029/2002JC001308

1100 Cheriton OM, Storlazzi CD, Rosenberger KJ (2016) Observations of wave transformation over a fringing coral reef and the importance of low-frequency waves and offshore water levels to runup, overwash, and coastal flooding. Journal of Geophysical Research: Oceans, 121 (5), pp. 3121-3140

Chini N, Stansby P, Leake J, Wolf J, Roberts-Jones J, Lowe J (2010) The impact of sea level rise and climate 1105 change on inshore wave climate: A case study for East Anglia (UK). Coastal Eng 57(11-12):973-984, https://doi.org/10.1016/j.coastaleng.2010.05.009

Church JA, et al. 2013. Sea Level Change, in: Stocker, TF, Qin, D, Plattner, G-K, Tignor, M, Allen, SK, Boschung, J, Nauels, A, Xia, Y, Bex, V, Midgley, PM (Eds.), Climate Change 2013: The Physical Science 1110 Basis. Contribution of Working Group I to the Fifth Assessment Report of the Intergovernmental Panel on Climate Change. Cambridge University Press, Cambridge, United Kingdom and New York, NY, USA, pp. 1137-1216. https://doi.org/10.1017/CBO9781107415324.026

Cipollini P, Benveniste J, Birol F, Joana Fernandes M, Obligis E, Passaro M, Ted Strub P, Valladeau G, 1115 Vignudelli S, Wilkin J (2017) Satellite altimetry in coastal regions, in: Satellite Altimetry Over Oceans and Land Surfaces. pp. 343-380. https://doi.org/10.1201/9781315151779

Cohn N, Ruggiero P (2016) The influence of seasonal to interannual nearshore profile variability on extreme water levels: Modeling wave runup on dissipative beaches. Coastal Engineering 115, 79-92.

Crawford W, Ballu V, Bertin X, and Karpytchev M (2015) The sources of deep ocean infragravity waves observed in the North Atlantic Ocean. Journal of Geophysical Research, 120, 5120-5133, doi:10.1002/2014JC010657

1125 Crosby SC, Cornuelle BD, O’Reilly WC, and Guza RT (2017) Assimilating global wave model predictions and deep-water wave observations in nearshore swell predictions. J Atmos. Ocean Technol, 34, $1823-1836$. 
doi:10.1175/JTECH-D-17-0003.1

Danilo C, Melgani F (2016) Wave Period and Coastal Bathymetry Using Wave Propagation on Optical Images.

1130 IEEE Transactions on Geoscience and Remote Sensing 54, 6307-6319. https://doi.org/10.1109/TGRS2016.2579266

De Bakker ATM, Tissier MFS, and Ruessink BG (2014) Shoreline dissipation of infragravity waves. Continental Shelf Research, 72, 73-82, doi: 10.1016/j.csr.2013.11.013.

1135

Defeo O, McLachlan A (2013) Global patterns in sandy beach macrofauna : Species richness, abundance, biomass and body size. Geomorphology 199:106-114

Di Luccio D, Benassai G, Budillon G, Mucerino L, Montella R, and Pugliese Carratelli E (2018) Wave run-up prediction and observation in a micro-tidal beach. Nat. Hazards Earth Syst. Sci., 18, 2841-2857

1140 Díaz-Sánchez R, López-Gutiérrez JS, Lechuga A, Negro V (2014) Runup variability due to time dependency and stochasticity in beach profiles. In: Green, AN and Cooper, JAG (eds.), Proceedings from the 13th International Coastal Symposium (Durban, South Africa), Journal of Coastal Research, Special Issue No. 70, pp. 001-006, ISSN 0749-0208

Díez J, Uriarte A, Cánovas V, Medina R (2017) A parametric model for dry beach equilibrium profiles. Coastal 1145 Engineering 127:134-144

Dodet G, Bertin X, Taborda R (2010) Wave climate variability in the North-East Atlantic Ocean over the last six decades. Ocean Modelling 31:120-131. https://doi.org/10.1016/j.ocemod.2009.10.010

Dodet G, Bertin X, Bruneau N, Fortunato A, Nahon A, Roland A (2013) Wave-current interactions in a wave-

1150 dominated tidal inlet. Journal of Geophysical Research-Ocean 118:1587-1905. http://dx.doi.org/10.1002/jgrc.20146

Dodet G, Leckler F, Sous D, Ardhuin F, Filipot JF, Suanez S (2018) Wave Runup Over Steep Rocky Cliffs. Journal of Geophysical Research: Oceans 123, 7185-7205. https://doi.org/10.1029/2018JC013967

Dodet G, Castelle B, Masselink G, Scott T, Davidson M, Floc’h F, Jackson D, Suanez S (2019) Beach recovery from extreme storm activity during the 2013/14 winter along the Atlantic coast of Europe. Earth Surface Processes and Landforms. https://doi.org/10.1002/esp.4500

1160 Fiedler JW, Brodie KL, McNinch JE, and Guza RT (2015) Observations of runup and energy flux on a lowslope beach with high-energy, long-period ocean swell. Geophysical Research Letters, 42, doi:10.1002/2015GL066,124 
Ford M, Merrifield MA, Becker JM (2018) Inundation of a low-lying urban atoll island: Majuro, Marshall 1165 Islands. Natural Hazards, 91(3), 1273-1297. doi:10.1007/s11069-018-3183-5

Fortunato AB, Freire P, Bertin X, Rodrigues M, Liberato MLR, Ferreira J (2017) A numerical study of the February 15, 1941 storm in the Tagus estuary. Cont Shelf Res 144:50-64. https://doi.org/10.1016/j.csr.2017.06.023.

1170

Gain L (1923) La prédiction des houles au Maroc. Revue Scientifique, 61 (19):605-615.

Gainza J, Rueda A, Camus P, Tomas A, Méndez FJ, Sano M, and Tomlinson R (2018) A meta-modelling approach for estimating long-term wave run-up and total water level on beaches. Journal of Coastal Research,

1175 34(2), 475-489. Coconut Creek (Florida), ISSN 0749-0208

Garcez-Faria A, Thornton E, Lippmann T, Stanton T (2000) Undertow over a barred beach. Journal Geophysical Research Oceans 105 (C7), 16999-17010

1180 Gawehn M, van Dongeren A, van Rooijen A, Storlazzi CD, Cheriton OM, Reniers A (2016) Identification and classification of very low frequency waves on a coral reef flat. Journal of Geophysical Research: Oceans, 121 (10), pp. 7560-7574.

Gemmrich, J, Thomas, B, Bouchard, R (2011) Observational changes and trends in northeast Pacific wave 1185 records. Geophysical Research Letters 38. https://doi.org/10.1029/2011GL049518.

Gouldby B, Méndez FJ, Guanche Y, Rueda A, Mínguez R (2014) A methodology for deriving extreme nearshore sea conditions for structural design and flood risk analysis. Coastal Eng 88:15-26, https://doi.org/10.1016/j.coastaleng.2014.01.012.

1190

Grant, W D, Madsen, OS, (1986) The continental shelf bottom boundary layer. Annual Review of Fluid Mechanics, 18, 265-305.

Gregory, JM, Griffies, SM, Hughes, CW, Lowe, JA, Church, JA, Fukimori, I, Gomez, N, Kopp, RE, Landerer,

1195 F, Cozannet, GL, Ponte, RM, Stammer, D, Tamisiea, ME, van de Wal, RSW, (2019). Concepts and Terminology for Sea Level: Mean, Variability and Change, Both Local and Global. Surv Geophys. https://doi.org/10.1007/s10712-019-09525-z.

Guérin, T, Bertin, X, Coulombier, T, de Bakker, A (2018) Impacts of wave-induced circulation in the surf zone 1200 on wave setup. Ocean Modelling\}, 123, 86-97.

Guimaraes, P V, Ardhuin, F, Sutherland, P, Accensi, M, Hamon, M, Pérignon, Y, Thomson, J, Benetazzo, A, and Ferrant, P (2018) A Surface KInematics Buoy (SKIB) for wave-current interactions studies Ocean Sci. 
Discuss, 2018. doi:10.5194/os-2018-45.

1205

Gulev, S K, Grigorieva, V, Sterl, A, and Woolf, D (2003) Assessment of the reliability of wave observations from voluntary observing ships: Insights from the validation of a global wind wave climatology based on voluntary observing ship data. J Geophys. Res, 108, C7, p. 3236.

1210 Gulev, SK, Grigorieva, V (2004) Last century changes in ocean wind wave height from global visual wave data. Geophysical Research Letters 31. https://doi.org/10.1029/2004GL021040.

Gulev, SK, Grigorieva, V (2006) Variability of the Winter Wind Waves and Swell in the North Atlantic and North Pacific as Revealed by the Voluntary Observing Ship Data. Journal of Climate 19, 5667-5685. 1215 https://doi.org/10.1175/JCLI3936.1.

Guza, RT, Thornton, EB (1981). Wave set-up on a natural beach. Journal of Geophysical Research, 86 (C5), pp. 4133-4137.

1220 Guza, R T, and E B Thornton (1982) Swash oscillations on a natural beach, Journal of Geophysical Research, 87, 483-491, doi:10.1029/JC087iC01p00483.

Guza, R T, and F Feddersen (2012). Effect of wave frequency and directional spread on shoreline runup, Geophys. Res. Letters, 39, L11607.

Hasselmann, K (1962), On the non-linear energy transfer in a gravity-wave spectrum part 1. General theory, Journal of Fluid Mechanics, 12 (04), 481-500, doi: 10.1017/S0022112062000373.

Hasselmann, K, Chapron, B, Aouf, L, Ardhuin, F, Collard, F, Engen, G, Hasselmann, S, Heimbach, P, Janssen, 1230 P, Johnsen, H, Krogstad, H, Lehner, S, Li, J-G, Li, X-M, Rosenthal, W, and Schulz-Stellenfleth, J (2012) The ERS SAR wave mode: a breakthrough in global ocean wave observations, in ERS Missions: 20 Years of Observing Earth, 165-198, European Space Agency, Noordwijk, The Netherlands

Hauser, D, Tison, C, Amiot, T, Delaye, L, Corcoral, N Castillan, P (2017) SWIM: The First Spaceborne Wave 1235 Scatterometer. IEEE Transactions on Geoscience and Remote Sensing 55, 3000-3014. https://doi.org/10.1109/TGRS2017.2658672

Hedges, T and H Mase (2004) Modified Hunt’s equation incorporating wave setup. J Waterw. Port Coast. Ocean Eng. 130, 109-113

Hemer, MA, Church, JA, Hunter, JR (2010) Variability and trends in the directional wave climate of the Southern Hemisphere. International Journal of Climatology 30, 475-491. https://doi.org/10.1002/joc.1900 
Hemer, MA, Fan, Y, Mori, N, Semedo, A, Wang, XL, (2013a) Projected changes in wave climate from a multi-

Hemer, MA, Katzfey, J, Trenham, CE (2013b) Global dynamical projections of surface ocean wave climate for a future high greenhouse gas emission scenario. Ocean Modelling, Ocean Surface Waves 70, 221-245. https://doi.org/10.1016/j.ocemod.2012.09.008

Hemer MA, Wang XL, Webb A., and COWCLIP contributors (2018) Report of the 2018 Meeting for the WCRP-JCOMM Coordinated Ocean Wave Climate Project, Paris, 21-23 May, 2018. JCOMM Technical Report 92. https://www.jcomm.info/index.php?option=com_oe\&task=viewDocumentRecord\&docID=22378

1255 Herbers, T H C and Burton, M C (1997) Nonlinear shoaling of directionally spread waves on a beach. J Geophys. Res, 102, C9, 21,101-21,114.

Herbers, T H C and Lentz, S J, “Observing directional properties of ocean swell with an acoustic doppler current profiler (ADCP),” J Atmos. Ocean Technol, 27, 210-225, 2010.

Herbers, T H C, Janssen, T T, Colbert, D B, and MacMahan, J H, “Observing ocean surface waves with gpstracked buoys,” J Atmos. Ocean Technol, 29, 944-959, 2012

Hoeke RK, McInnes KL, Kruger JC, McNaught RJ, Hunter JR, Smithers SG (2013) Widespread inundation of 1265 Pacific islands triggered by distant-source wind-waves. Global and Planetary Change 108:128-138. doi:10.1016/j.gloplacha.2013.06.006

Hoeke RK, McInnes KL, O’Grady JG (2015) Wind and Wave Setup Contributions to Extreme Sea Levels at a Tropical High Island: A Stochastic Cyclone Simulation Study for Apia, Samoa. J Mar. Sci. Eng 3:1117-1135.

1270 Holman, RA, Sallenger Jr., AH (1985). Setup and Swash on a natural beach. Journal of Geophysical Research, 90 (C1), pp. 945-953.

Holman RA (1986) Extreme value statistics for wave run-up on a natural beach. Coastal Engineering 9: 527544.

1275 Holman, RA, Stanley, J (2007) The history and technical capabilities of Argus. Coastal Engineering, The CoastView Project: Developing coastal video monitoring systems in support of coastal zone management 54, 477-491. https://doi.org/10.1016/j.coastaleng.2007.01.003

Holman R, Plant NG, Holland KT (2013). cBathy: A robust algorithm for estimating nearshore bathymetry. Journal of Geophysical Research C: Oceans 118:2595-2609. doi:10.1002/jgrc.20199.

Holman, R, Haller, MC (2013) Remote sensing of the nearshore. Ann Rev Mar Sci 5, 95-113. 
https://doi.org/10.1146/annurev-marine-121211-172408.

Holthuijsen, L H, Herman, A, and Booij, N, "Phase-decoupled refraction-diffraction for spectral wave models," Coastal Eng, 49, 91-305, 2003.

1285

Hunt IA (1959) Design of Seawalls and Breakwaters. Journal of the Waterways and Harbors Division, 85, 123152

Idier D, Bertin X, Thompson P, Pickering MD (submitted) Interactions Between Mean Sea-level, Tide, Surge and Flooding: Mechanisms and Contributions to Sea Level Variations at the Coast. Submitted to Surveys in Geophysics (SI).

Inch, K, M Davidson, G Masselink, and P Russell, 2017. Observations of nearshore infragravity wave dynamics under high energy swell and wind-wave conditions, Continental Shelf Research, 138, 19-31, doi: 1295 10.1016/j.csr.2017.02.010.

Iribarren CR, Nogales C (1949). Protection des Ports, in: XVIIth International Navigation Congress. Lisbon, Portugal, pp. 31-80.

1300 Izaguirre, C, Méndez, FJ, Menéndez, M, Losada, IJ (2011) Global extreme wave height variability based on satellite data. Geophysical Research Letters 38. https://doi.org/10.1029/2011GL047302.

Jackson, F C, Walton, W T, and Baker, P L, “Aircraft and satellite measurement of ocean wave directional spectra using scanning-beam microwave radars,” J Geophys. Res, 90, 987-1004, 1985.

1305

Janssen, T T, Herbers, T H C, and Battjes, J A, “Generalized evolution equation for nonlinear surface gravity waves over two-dimensional topography,” J Fluid Mech, 552, 393-418, 2006.

Jensen, RE, VR Swail, R H Bouchard, RE Riley, T J Hesser, M Blaseckie, and C MacIsaac (2015) Field

1310 Laboratory for Ocean Sea State Investigation and Experimentation: FLOSSIE Intra-Measurement Evaluation of 6N Wave Buoy Systems, Proceedings of the 114th International Workshop on Wave Hindcasting and Forecasting \& 5th Coastal Hazard Symposium.

Ji, C, Zhang, Q, Wu, Y (2018) An empirical formula for maximum wave setup based on a coupled wave-current

1315 model. Ocean Engineering 147, 215-226

Jia, G, Taflanidis, AA (2013) Kriging metamodeling for approximation of high-dimensional wave and surge responses in real-time storm/hurricane risk assessment. Comput Methods Appl Mech Eng, 261, 24-38.

1320 Karunarathna H, Caraballo JH, Kuriyama Y, Mase H, Ranasinghe R, Reeve DE (2016) Linkages between sediment composition, wave climate and beach profile variability at multiple timescales. Marine Geology 381: 
194-208

Kennedy, A, Westerink, J, Smith, J, Hope, M, Hartman, M, Taflanidis, A, Tanaka, S, Westerink, H, Cheung, K,

1325 Smith, T, Hamann, M, ad Minamide, M, Ota, A, Dawson, C, 2012. Tropical cyclone inundation potential on the hawaiian islands of Oahu and Kauai. Ocean Modelling 52-53, 54-68.

Kerbaol, V, Chapron, B, and Vachon, P (1998) Analysis of ERS-1/2 synthetic aperture radar wave mode imagettes. J Geophys. Res, 103, C4, 7833-7846..

1330

Kim SY, Yasuda T, Mase H (2008) Numerical analysis of effects of tidal variations on storm surges and waves. App Ocean Res 30(4):311-322, https://doi.org/10.1016/j.apor.2009.02.003.

Komar P (1998) Beach processes and sedimentation, 2nd edn. Prentice Hall, New Jersey, USA

1335

Kudryavtsev, V, Yurovskaya, M, Chapron, B, Collard, F, and Donlon, C, "Sun glitter imagery of surface waves. part 2: Waves transformation on ocean currents,” J Geophys. Res, 122, 2017. doi:10.1002/2016JC012426.

Laugel A, Menendez M, Benoit M, Mattarolo G, Méndez F (2014) Wave climate projections along the French

coastline: Dynamical versus statistical downscaling methods, Ocean Model 84:35-50, https://doi.org/10.1016/j.ocemod.2014.09.002.

Longuet-Higgins, M, and R Stewart, 1962. Radiation stress and mass transport in gravity waves, with application to surf beats. Journal of Fluid Mechanics, 13 (4), 481-504.

Longuet-Higgins, M S, Cartwright, D E, and Smith, N D, "Observations of the directional spectrum of sea waves using the motions of a floating buoy,” in Ocean Wave Spectra, proceedings of a conference, Easton, Maryland, 111-136, National Academy of Sciences, Prentice-Hall, 1963.

1350 Longuet-Higgins, MS, Stewart, R, 1964. Radiation stresses in water waves; a physical discussion, with applications. Deep Sea Research and Oceanographic Abstracts. 11. Elsevier, 529-562.

Luijendijk A, G Hagenaars, R Ranasinghe, F Baart, G Donchyts, S Aarninkhof, 2018. The state of the world's beaches. Scientific Reports, 8, 6641.

1355 Lumpkin, T Ozgokmen, L Centurioni (2016) Advances in the Application of Surface Drifters, Annual Review of Marine Science, 9:6.1-6.23, doi: 10.1146/annurev-marine-010816-060641

Magne, R, Belibassakis, K, Herbers, T H C, Ardhuin, F, O’Reilly, W C, and Rey, V, “Evolution of surface gravity waves over a submarine canyon,” J Geophys. Res, 112, p. C01002, 2007. doi:10.1029/2005JC003035. 
Malhadas, MS, Leitão, PC, Silva, A, Neves, R, 2009. Effect of coastal waves on sea-level in Óbidos Lagoon, Portugal. Continental Shelf Research 29 (9), 1240-1250.

Marchesiello, P, Benshila, R, Almar, R, Uchiyama, Y, McWilliams, JC, Shchepetkin, A, 2015. On 1365 tridimensional rip current modeling. Ocean Modelling, Waves and coastal, regional and global processes 96, 36-48. https://doi.org/10.1016/j.ocemod.2015.07.003.

Martins, K, Blenkinsopp, CE, Power, HE, Bruder, B, Puleo, JA, Bergsma, EWJ, 2017. High-resolution monitoring of wave transformation in the surf zone using a LiDAR scanner array. Coastal Engineering 128, 37-

1370 43. https://doi.org/10.1016/j.coastaleng.2017.07.007.

Martins, K, Blenkinsopp, CE, Deigaard, R, Power, HE (2018) Energy Dissipation in the Inner Surf Zone: New Insights From LiDAR-Based Roller Geometry Measurements. Journal of Geophysical Research: Oceans, in press.

1375

Mase, H, 1989. Random wave runup height on gentle slope. J Waterw. Port Coast. Ocean Eng. 115, 649-661.

Masselink, G, Russell, P, Turner, I, Blenkinsopp, C, 2009. Net sediment transport and morphological change in the swash zone of a high-energy sandy beach from swash event to tidal cycle time scales. Marine Geology 267,

1380 18-35. https://doi.org/10.1016/j.margeo.2009.09.003

Mastenbroek, C, Burgers, G, Janssen, PAEM (1993) The dynamical coupling of a wave model and a storm surge model through the Atmospheric Boundary Layer. \Journal of physical Oceanography, 23, 1856-1866.

1385 Matsuba, Y, Sato, S (2018) Nearshore bathymetry estimation using UAV Coastal Engineering Journal 60, 5159. https://doi.org/10.1080/21664250.2018.1436239.

McWilliams, JC, Restrepo, JM, Lane, EM (2004) An asymptotic theory for the interaction of waves and currents in coastal waters. Journal of Fluid Mechanics, 511, 135-178.

1390

Mentaschi L, Vousdoukas MI, Voukouvalas E, Dosio A, Feyen L (2017) Global changes of extreme coastal wave energy fluxes triggered by intensified teleconnection patterns. Geophysical Research Letters 44: 24162426. doi:10.1002/2016GL072488

1395 Melet A, Almar R, Meyssignac B (2016) What dominates sea level at the coast: a case study for the Gulf of Guinea. Ocean Dynamics 66:623-636

Melet A, Meyssignac B, Almar R, Le Cozannet G (2018) Under-estimated wave contribution to sea-level rise. Nature Climate Change 8:234-239.

Melet A, Meyssignac B, Almar R, Le Cozannet G (2019) Reply to ‘’Waves do not contribute to global sea-level 
rise”. Nat Clim Change 9:3. https://doi.org/10.1038/s41558-018-0378-4.

Menéndez, M, Méndez, FJ, Losada, IJ, Graham, NE (2008) Variability of extreme wave heights in the northeast Pacific Ocean based on buoy measurements. Geophysical Research Letters 35. https://doi.org/10.1029/2008GL035394.

Merrifield MA, Becker JM, Ford M, Yao Y (2014) Observations and estimates of wave-driven water level 1405 extremes at the Marshall Islands. Geophys. Res.Lett. 41:7245-7253. doi:10.1002/2014GL061005

Moura, T, Baldock, TE (2017). Remote sensing of the correlation between breakpoint oscillations and infragravity waves in the surf and swash zone. Journal of Geophysical Research: Oceans, 122 (4), 3106-3122.

Muis S, Verlaan M, Winsemius HC, Aerts JC, Ward PJ (2016) A global reanalysis of storm surges and extreme sea levels. Nat. Commun. 7:11969

1410 Munk, W H and Traylor, M A (1947) Refraction of ocean waves: a process linking underwater topography to beach erosion. Journal of Geology, LV, 1-26.

Moghimi, S, Klingbeil, K, Gräwe, U, Burchard, H (2013) A direct comparison of a depth-dependent radiation stress formulation and a vortex force formulation within a three dimensional coastal ocean model. Ocean

1415 Modelling 70, 132-144.

Morim, J, Hemer, M, Cartwright, N, Strauss, D, Andutta, F (2018) On the concordance of 21st century windwave climate projections. Global and Planetary Change 167, 160-171. https://doi.org/10.1016/j.gloplacha.2018.05.005.

Neumann, B, Vafeidis, AT, Zimmermann, J, Nicholls, RJ, 2015. Future Coastal Population Growth and 1420 Exposure to Sea-Level Rise and Coastal Flooding - A Global Assessment. PLoS One 10. https://doi.org/10.1371/journal.pone.0118571

Nicolae-Lerma, A, Pedreros, R, Robinet, A, Sénéchal, N (2017). Simulating wave setup and runup during storm conditions on a complex barred beach. Coastal Engineering, 123, pp. 29-41.

Nicolle, A, Karpytchev, M Benoit, M (2009) Amplification of the storm surges in shallow waters of the Pertuis Charentais (Bay of Biscay, France). Ocean Dynamics, 59: 921. https://doi.org/10.1007/s10236-009-0219-0.

Nicholls, RJ, Cazenave, A, 2010. Sea-Level Rise and Its Impact on Coastal Zones. Science 328, 1517-1520.

Nielsen P, DJ Hanslow, 1991. Wave runup distributions on natural beaches, J Coast. Res., 1139-1152.

Nouguier, F, Chapron, B, Collard, F, Mouche, A, Rascle, N, Ardhuin, F, and Wu, X, "Sea surface kinematics 1435 from near-nadir radar measurements," IEEE Trans. on Geosci. and Remote Sensing, 2018. 
doi:10.1109/TGRS2018.2833200.

O’Reilly, W C and Guza, R T, “A comparison of two spectral wave models in the Southern California Bight,” Coastal Eng, 19, 263-282, 1993.

1440

Overeem, I, Anderson, RS, Wobus, CW, Clow, GD, Urban, FE, Matell, N, 2011. Sea ice loss enhances wave action at the Arctic coast. Geophysical Research Letters 38. https://doi.org/10.1029/2011GL048681

Ozer, J, Padilla-Hernandez, R, Monbaliub, J, Fanjul, E A, Albiach, J C C, Osuna, P, Yu, J C, and Wolf, J, “A

1445 coupling module for tides, surges and waves,” Coastal Eng, 41, 1-3, 95-124, 2000.

Passarella M, Goldstein EB, De Muro S, Coco G (2018) The use of genetic programming to develop a predictor of swash excursion on sandy beaches. Nat. Hazards Earth Syst Sci 18:599-611. https://doi.org/10.5194/nhess18-599-2018.

1450

Passaro, M, Fenoglio-Marc, L, and Cipollini, P, "Validation of significant wave height from improved satellite altimetry in the German Bight,” IEEE Trans. on Geosci. and Remote Sensing, 53, 2146-2156, 2015.

Pearson J, Bruce T, Allsop N (2001) Prediction of wave overtopping at steep seawalls-variabilities and 1455 uncertainties. Proceedings Waves. vol. 1, pp. 1797-1808.

Pedreros R, Idier D, Muller H, Lecacheux S, Paris F, Yates-Michelin M, Dumas F, Pineau-Guillou L, Sénéchal N (2018) Relative contribution of wave setup to the storm surge: observations and modeling based analysis in open and protected environments (Truc Vert beach and Tubuai island). In: Shim, J-S; Chun, I, and Lim, HS

1460 (eds.), Proceedings from the International Coastal Symposium (ICS) 2018 (Busan, Republic of Korea). Journal of Coastal Research, Special Issue 85:1046-1050. Coconut Creek (Florida), ISSN 0749-0208.

Peltier, WR, Tushingham, AM, 1989. Global sea level rise and the greenhouse effect: might they be connected? Science 244, 806-810. https://doi.org/10.1126/science.244.4906.806.

1465

Perez, J, Menendez, M, Camus, P, Mendez, FJ, Losada, IJ 2015) Statistical multi-model climate projections of surface ocean waves in Europe, Ocean Modelling, 96, 161-170, https://doi.org/10.1016/j.ocemod.2015.06.001.

Pianca, C, Holman, R, and Siegle, E (2015). Shoreline variability from days to decades: Results of long-term video imaging. Journal of Geophysical Research: Oceans, 120(3):2159-2178

Poate, TG, McCall, RT, Masselink, G, 2016. A new parameterisation for runup on gravel beaches. Coastal Engineering 117, 176-190. Doi: 10.1016/j.coastaleng.2016.08.003.

1475 Pomeroy, A, Lowe, R, Symonds, G, Van Dongeren, A, Moore, C, 2012. The dynamics of infragravity wave 
transformation over a fringing reef. Journal of Geophyiscal Research 117. doi:10.1029/2012JC008310.

Poupardin, A, Idier, D, de Michele, M, Raucoules, D, 2016. Water Depth Inversion From a Single SPOT-5 Dataset. IEEE Transactions on Geoscience and Remote Sensing 54, 2329-2342. 1480 https://doi.org/10.1109/TGRS2015.2499379

Powell, KA, 1990. Predicting Short Term Profile Response for Shingle Beaches. Hydraulics Research Limited, Wallingford, Oxfordshire. Report SR2 19.

1485 Power H E, Gharabaghi B, Bonakdari H, Robertson B, Atkinson A L, Baldock T E, 2019. Prediction of wave runup on beaches using Gene-Expression Programming and empirical relationships. Coastal Engineering 144, 47-61.

Pullen T, Allsop N, Bruce T, Kortenhaus A, Schüttrumpf H, Van der Meer J (2007) EurOtop Wave Overtopping of Sea Defences and Related Structures: Assessment Manual. Environment Agency, UK

Purkis, S J (2018). Remote Sensing Tropical Coral Reefs: The View from Above. Annual Review of Marine Science, 10(1), 149-168. doi:10.1146/annurev-marine-121916-063249

1495 Quilfen, Y, Yurovskaya, M, Chapron, B, and Ardhuin, F, "Storm waves sharpening in the Agulhas current: satellite observations and modeling," Remote sensing of Environment, 216, 561-571, 2018. doi:10.1016/j.rse.2018.07.020.

Raubenheimer, B, Guza, R, Elgar, S, 2001. Field observations of wave-driven setdown and setup. Journal of 1500 Geophysical Research Oceans 106 (C3), 4629-4638.

Raucoules D, de Michele M, Idier D, Smai F, Foumelis M, Boulahya F, Volden E, Drakopoulou V, Przemysław M (2019) BATHYSENT - A method to retrieve coastal bathymetry from sentinel-2). IEEE International Geoscience and Remote Sensing Symposium (IGARSS).

Rawat, A, F Ardhuin, V Ballu, W Crawford, C Corela, and J Aucan, 2014. Infragravity waves across the oceans. Geophysical Research Letters, 41 (22), 7957-7963, doi:10.1002/2014GL061604.

Revell, D L, R Battalio, B Spear, P Ruggiero, and J Vandever (2011), A methodology for predicting future 1510 coastal hazards due to sea-level rise on the California Coast, Clim. Change, 109, 1-26, doi:10.1007/s10584-011$0315-2$.

Rhein, M, et al. 2013. Observations: Ocean, in: Stocker, TF, Qin, D, Plattner, G-K, Tignor, M, Allen, SK, Boschung, J, Nauels, A, Xia, Y, Bex, V, Midgley, PM (Eds.), Climate Change 2013: The Physical Science Basis. Contribution of Working Group I to the Fifth Assessment Report of the Intergovernmental Panel on 1515 Climate Change. Cambridge University Press, Cambridge, United Kingdom and New York, NY, USA, pp. 255- 
316. Doi: 10.1017/CBO9781107415324.010.

Roberts T M, P Wang, N C Kraus, 2010. Limits of Wave Runup and Corresponding Beach-Profile Change from Large-Scale Laboratory Data. Journal of Coastal Research, 26, 184-198

1520

Rohmer J, Idier D (2012) A meta-modelling strategy to identify the critical offshore conditions for coastal flooding. Nat. Hazards Earth Syst Sci 12:2943-2955. https://doi.org/10.5194/nhess-12-2943-2012.

Rohmer, J, Lecacheux, S, Pedreros, R et al. Nat Hazards (2016) Dynamic parameter sensitivity in numerical 1525 modelling of cyclone-induced waves: a multi-look approach using advanced meta-modelling techniques, Natural Hazards, 84: 1765. https://doi.org/10.1007/s11069-016-2513-8.

Roland, A and Ardhuin, F, "On the developments of spectral wave models: numerics and parameterizations for the coastal ocean,” Ocean Dynamics, 64, 6, 833-846, 2014. doi:10.1007/s10236-014-0711-z.

1530

Romano A, Bellotti G, Briganti R, Franco L (2015) Uncertainties in the physical modelling of the wave overtopping over a rubble mound breakwater: The role of the seeding number and of the test duration. Coastal Eng 103:15-21. https://doi.org/10.1016/j.coastaleng.2015.05.005.

1535 Romeiser, R and H C Graber (2018), Advanced Ocean Wave Retrieval from Time Series of Spotlight SAR Subaperture Images, EUSAR 2018; 12th European Conference on Synthetic Aperture Radar.

Rueda, A , Gouldby, B , Méndez, F , Tomás, A , Losada, I , Lara, J and Díaz Simal, P (2016) Coastal flood risk assessment. J Flood Risk Manage, 9: 390-401. doi:10.1111/jfr3.12204.

1540 Rueda A, Vitousek S, Camus P, Tomas A, Epejo A, Losada IJ, Barnard P, Erikson L, Ruggiero P, Reguero BG, Mendez FJ (2017) A global classification of coastal flood hazard climates associated with large-scale oceanographic forcing. Scientific Reports 7:5038.

Ruessink, BG, Kleinhans, MG, van den Beukel, PGL, 1998. Observations of swash under highly dissipative conditions. J Geophys. Res. 103, 3111-3118. https://doi.org/10.1029/97JC02791.

1545

Ruessink, B G, 2010. Observations of turbulence within a natural surf zone, Journal of Physical Oceanography, 40, 2696-2712, doi:10.1175/2010JPO4466.1.

Ruggiero P, Komar PD, Marra JJ, McDougal WG, Beach RA (2001) Wave runup, extreme water levels and the 1550 erosion of properties backing beaches. J Coastal Res 17: 407-419

Ruggiero P, Holman R, Beach R (2004) Wave run-up on a high-energy dissipative beach. Journal of Geophysical Research C: Oceans 109(6):C06025, 1-12. doi:10.1029/2003JC002160. 
1555 Rusu L, Bernardino M, Guedes Soares C (2011) Modelling the influence of currents on wave propagation at the entrance of the Tagus estuary. Ocean Eng 38(10):1174-1183. https://doi.org/10.1016/j.oceaneng.2011.05.016

Saville, T, 1961. Experimental determination of wave set-up. Proceedings of the Second Technical Conference on Hurricanes, US Dept. of Commerce, National Hurricane Res. Proj, 1961. pp. 242-252.

1560

Semedo, A, Sušelj, K, Rutgersson, A, Sterl, A (2010) A Global View on the Wind Sea and Swell Climate and Variability from ERA-40. Journal of Climate 24, 1461-1479. https://doi.org/10.1175/2010JCLI3718.1.

Senechal N, Coco G, Bryan KR, Holman RA (2011) Wave runup during extreme storm conditions. J Geophys. 1565 Res 116:C07032. doi:10.1029/2010JC006819

Seneviratne SI, et al. (2012) Changes in Climate Extremes and their Impacts on the Natural Physical Environment, in: Field, CB, Barros, V, Stocker, TF, Dahe, Q (Eds.), Managing the Risks of Extreme Events and Disasters to Advance Climate Change Adaptation. Cambridge University Press, Cambridge, pp. 109-230. doi:10.1017/CBO9781139177245.006

Send, Uwe, Weller, Robert A, Wallace, Doug, Chavez, Francisco, Lampitt, Richard, Dickey, Tommy, Honda, Makio, Nittis, Kostas, Lukas, Roger, McPhaden, Mike and Feely, Richard (2010) OceanSITES Hall, J, Harrison, DE and Stammer, D (eds.) In Proceedings of OceanObs'09: Sustained Ocean Observations and 1575 Information for Society, Vol. 2. European Space Agency. pp. 913-922.

Sepulveda, H H, Queffeulou, P, and Ardhuin, F, “Assessment of SARAL AltiKa wave height measurements relative to buoy, Jason-2 and Cryosat-2 data,” Marine Geodesy, 38, S1, 449-465, 2015. doi:10.1080/01490419.2014.1000470.

1580

Serafin KA, Ruggiero P, Stockdon HF (2017) The relative contribution of waves, tides, and nontidal residuals to extreme total water levels on US West Coast sandy beaches. Geophysical Research Letters 44:1839-1847

Sheremet, A, Staples, T, Ardhuin, F, Suanez, S, and Fichaut, B, 2014, Observations of large infragravity-wave run-up at Banneg island, France, Geophys. Res. Lett, 41, 2014, doi: 10.1002/2013gl058880

Slangen, A B A, M Carson, C A Katsman, R S W van de Wal, A Koehl, L L A Vermeersen, and D Stammer, 2014: Projecting twenty-first century regional sea-level changes. Climate Change, 124, 317.

Smit, PB, Janssen, TT, Herbers, THC, Taira, T, Romanowicz, BA (2018) Infragravity Wave Radiation Across 1590 the Shelf Break. Journal of Geophysical Research: Oceans 123, 4483-4490. https://doi.org/10.1029/2018JC013986.

Smith JA (2006) Wave-current interactions in finite-depth. J Phys. Oceanogr, 36, 1403-1419 
1595 Stockdon HF, Holman RA, Howd PA, Sallenger Jr AH (2006) Empirical parameterization of setup, swash, and runup. Coastal Engineering 53:573-588. doi:10.1016/j.coastaleng.2005.12.005

Stockdon HF, Thompson DM, Plant NG, Long JW (2014) Evaluation of wave runup predictions from numerical and parametric models, Coast. Eng. 92, 1-11

1600

Stopa JE, Ardhuin F, and Girard-Ardhuin F (2016) Wave climate in the Arctic 1992-2014: seasonality and trends. The Cryosphere. 10, 1605-1629. doi:10.5194/tc-10-1605-2016

Stopa JE (2018) Wind forcing calibration and wave hindcast comparison using multiple reanalysis and merged 1605 satellite wind datasets. Ocean Modelling, 127, 55-69,. doi:10.1016/j.ocemod.2018.04.008

Stopa JE, Ardhuin F, Stutzmann E, Lecocq T (2019) Sea state trends and variability: consistency between models, altimeters, buoys, and seismic data (1979-2016). Journal of Geophysical Research: Oceans 0. https://doi.org/10.1029/2018JC014607

The WAVEWATCH III R Development Group, "User manual and system documentation of WAVEWATCH III R version 5.16,” Tech. Note 329, NOAA/NWS/NCEP/MMAB, College Park, MD, USA, 2016. 326 pp. + Appendices.

1615 Thompson RORY, Hamon BV (1980) Wave setup of harbor water levels. Journal of Geophysical Research: Oceans 85, 1151-1152. https://doi.org/10.1029/JC085iC02p01151

Thomson J (2012) Wave breaking dissipation observed with ”swift” drifters. J Atmos. Ocean Technol, 29, 1866-1882. doi:10.1175/JTECH-D-12-00018.1

1620

Tomás A, Méndez F, Medina R, Jaime F, Higuera P, Lara J, Ortiz M, Álvarez de Eulate M (2016) Coastal flooding maps in Spain. J Flood Risk Manage 9: 289-305. https://doi.org/10.1111/jfr3.12198.

Taflanidis AA, Kennedy AB, Westerink JJ, Smith J, Cheung KF, Hope M, Tanaka S (2013) Rapid Assessment of Wave and Surge Risk during Landfalling Hurricanes: Probabilistic Approach, Journal of Waterway, Port, 1625 Coastal, and Ocean Engineering, 139, 3, 171-182, doi:10.1061/(ASCE)WW1943-5460.0000178.

Torres-Freyermuth A, Puleo J A, and Pokrajac D (2013) Modeling swash-zone hydrodynamics and shear stresses on planar slopes using reynolds-averaged navierstokes equations. J Geophys. Res, 118, 1019-1033. doi:10.1002/jgrc.20074

Tuah H, Hudspeth RT (1982) Comparisons of numerical random sea simulations. J Waterw Port Coast. Ocean Div. ASCE 108(4):569-584 
Turner IL, Harley MD, Drummond CD (2016) UAVs for coastal surveying. Coastal Engineering 114, $19-24$.

Van der Meer JW, Stam C-JM (1992) Wave Runup on Smooth and Rock Slopes of Coastal Structures. Journal of Waterway, Port, Coastal, and Ocean Engineering 118, 534-550. doi:10.1061/(ASCE)0733950X(1992)118:5(534)

1640

Vitousek S, Barnard PL, Fletcher CH, Frazer N, Erikson L, Storlazzi CD (2017) Doubling of coastal flooding frequency within decades due to sea-level rise. Nature 7:1399

Vousdoukas MI, Velegrakis AF, Dimou K, Zervakis V, Conley DC (2009) Wave run-up observations in microtidal, sediment-starved pocket beaches of the Eastern Mediterranean. Journal of Marine Systems 78:S37-

1645 S47.

Vousdoukas, MI, Wziatek, D and Almeida, LP, 2012. Coastal vulnerability assessment based on video wave run- up observations at a mesotidal, steep-sloped beach, Ocean Dynamics, 62(1), 123-137.

Vousdoukas MI et al. (2016) Developments in large-scale coastal flood hazard mapping. Nat. Hazards Earth Syst. Sci 16:1841-1853

1650 Vousdoukas MI, Mentaschi L, Voukouvalas E, Verlaan M, Feyen L (2017) Extreme sea levels on the rise along Europe’s coasts. Earth’s Future 5:304-323

Vousdoukas MI, Mentaschi L, Voukouvalas E, Verlaan M, Jevrejeva S, Jackson LP, Feyen L (2018a) Global probabilistic projections of extreme sea levels show intensification of coastal flood hazard. Nature Communications 9:2360

1655 Vousdoukas MI, Mentaschi L, Voukouvalas E, Bianchi A, Dottori F, Feyen L (2018b) Climatic and socioeconomic controls of future coastal flood risk in Europe. Nature Climate Change 8:776-780

Wahl, T, Haigh, I D, Nicholls, R J, Arns, A, Dangendorf, S, Hinkel, J, Slangen, A B A Understanding extreme sea levels for broad-scale coastal impact and adaptation analysis. Nature Communications 8, 16075 (2017).

Walstra, D J R, Roelvink, J, and Groeneweg, J, “Calculation of wave-driven currents in a 3D mean flow

1660 model,” in Proceedings of the 27th international conference on coastal engineering, Sydney, vol. 2, 1050-1063, ASCE, 2000.

Wandres M, Pattiaratchi C, Hemer MA (2017) Projected changes of the southwest Australian wave climate under two atmospheric greenhouse gas concentration pathways. Ocean Modelling 117:70-87

1665 Wang, X L, and Swail V R (2001) Changes in extreme wave heights in Northern Hemisphere oceans and related atmospheric circulation regimes. J Climate, 14, 2204-2221, doi:10.1175/15200442(2001)014,2204:COEWHI2.0.CO;2.

Wang XL, Swail VR (2006) Climate change signal and uncertainty in projections of ocean wave heights. Clim 
Wang XL, Feng Y, Swail VR (2014) Changes in global ocean wave heights as projected using multimodel CMIP5 simulations. Geophysical Research Letters 41, 1026-1034. Doi: 10.1002/2013GL058650

1675 Wassing F (1957) Model investigation on wave run-up carried out in the Netherlands during the past twenty years, in: Proccedings of the 6th International Coastal Engineering Conference, American Society of Civil Engineers, 1957, 700-714.

Wenneker I, Spelt B, Peters H, de Ronde J (2016) Overview of 20 years of field measurements in the coastal 1680 zone and at the Petten sea dike in the Netherlands. Coastal Engineering 109, 96-113. https://doi.org/10.1016/j.coastaleng.2015.12.009

Williams HE, Briganti R, Pullen T (2014) The role of offshore boundary conditions in the uncertainty of numerical prediction of wave overtopping using non-linear shallow water equations. Coas. En. 89:30-44. 1685 https://doi.org/10.1016/j.coastaleng.2014.03.003

WISE Group, (2007) Wave modelling - the state of the art. Progress in Oceanography, 75, 603-674, 2007. doi:10.1016/j.pocean.2007.05.005

1690 Woodworth PL, Melet A, Marcos M, Ray RD, Wöppelmann G, Sasaki YN, Cirano M, Hibbert A, Huthnance JM, Monserrat S, Merrifield MA (2019) Forcing Factors Affecting Sea Level Changes at the Coast. Surv Geophys. https://doi.org/10.1007/s10712-019-09531-1

Wong PP et al. In Climate Change 2014: Impacts, Adaptation, and Vulnerability (eds Field, C B et al.) 361-409 1695 (IPCC, Cambridge Univ. Press, 2014).

Wright LD, Short AD (1984) Morphodynamic variability of surf zones and beaches: a synthesis. Marine geology 56, 93-118.

1700 Xie L, Pietrafesa LJ and Wu K (2003) A numerical study of wave-current interaction through surface and bottom stresses: coastal ocean response to hurricane Fran of 1996. Journal of Geophysical Research: Ocean, 108, 3049-3066.

Young IR, Zieger S, Babanin AV, (2011) Global Trends in Wind Speed and Wave Height. Science 332, 4511705 455. https://doi.org/10.1126/science.1197219

Young IR, Ribal A (2019) Multiplatform evaluation of global trends in wind speed and wave height. Science 364, 548. https://doi.org/10.1126/science.aav9527 
1710 Yu X, Pan W, Zheng X, Zhou S, Tao X (2017) Effects of wave-current interaction on storm surge in the Taiwan Strait: Insights from Typhoon Morakot. Continental Shelf Research, 146, 47-57, doi : 10.1016/j.csr.2017.08.009

Zhang WZ, Shi F, Hong HS, Shang SP, Kirby JT (2010) Tide-surge Interaction Intensified by the Taiwan Strait. J Geophys. Res, 115, C06012, doi:10.1029/2009JC005762

1715

Zijlema M, Stelling G, and Smit P (2011) Swash: An operational public domain code for simulating wave fields and rapidly varied flows in coastal waters, Coastal Eng, 58, 992-1012. doi:10.1016/j.coastaleng.2011.05.015 